\title{
VINCULACIONES POLÍTICAS EN UN RÉGIMEN DE BANCA LIBRE: EL CASO DE LA CRISIS BANCARIA DE 1878 EN CHILE*
}

IGNACIO BRIONES

Universidad Adolfo Ibáñez ${ }^{\mathrm{a}}$

Political links in a free banking system: the case of the Chilean banking crisis of 1878

\begin{abstract}
In 1878 Chile experienced a banking crisis which brought an end to the Chilean free-banking period based on convertibility initiated in 1860. Using monthly bank balance sheets and other primary sources, I analyze the period and argue that one important explanation for the crisis was the growing relationship between banks and government through state loans to finance fiscal deficits and privileges to the issuing banks. I claim that the crisis emerged from a large bank loan in late 1877 which induced over-issuance and depreciation expectations leading, logically, to a bank run. The Chilean case provides valuable evidence of an element frequently neglected by the free-banking literature: the links between banks and government.
\end{abstract}

Keywords: Free-banking, competing notes, banking crisis, deficit monetization, government privileges.

JEL Codes: G01, G21, H30, N26, N20, P16

* Received 29 May 2015. Accepted 14 January 2016. The author is very grateful to the Editor of the Journal of Iberian and Latin American Economic History and three anonymous referees for their valuable comments and suggestions.

a School of Government, Universidad Adolfo Ibáñez, Avenida Diagonal las Torres, 2640, Peñalolén, Santiago, Chile. Phone: (56-2)23311361. Email: ignacio.briones@uai.cl 


\section{RESUMEN}

En 1878 un pánico bancario pone fin al periodo de banca libre basado en la convertibilidad metálica e iniciado en Chile en 1860. En este trabajo analizo el periodo apoyándome en los balances mensuales de bancos y otras fuentes primarias. Argumento que una causa importante de la crisis fue la creciente relación entre banca y gobierno a través de préstamos al Estado y privilegios a los bancos de emisión. Muestro que la crisis se asocia con un importante préstamo con los bancos a fines de 1877. Sostengo que éste inducía a la sobreemisión y a expectativas de depreciación cuyo resultado racional era una corrida bancaria. El caso chileno proporciona evidencia valiosa sobre un elemento que ha recibido relativa poca importancia en la literatura de banca libre: los vínculos entre bancos y gobierno.

Palabras claves: Banca libre, emisión competitiva, crisis banacaria, déficit fiscal, privilegios de emisión

\section{INTRODUCCIÓN}

La experiencia de países con sistemas de banca libre -caracterizados por la emisión descentralizada de dinero a través de bancos privados sujetos a mínimas regulaciones- ha recibido una larga atención por parte de la historia económica. La literatura ha documentado una serie de casos entre los que destacan los de Escocia (1716-1844) y Estados Unidos (1837-61) (ver Briones y Rockoff 2005 para una revisión). En América Latina varios países habrían tenido alguna forma de banca libre durante el siglo XIX (Schuler 1992, Zegarra 2013a, 2014), siendo las experiencias mejor estudiadas las de Colombia (Echeverri 1991, Meisel 1992), del Perú (Morón 1993, Zegarra 2013b) y de Chile (Santelices 1893, Espinoza 1909, Millar 1994, Ross 2003, Briones 2004, Jeftanovic y Lüders 2007).

Un tema central en la literatura ha sido la relación entre banca libre y estabilidad financiera. Teóricamente un sistema de banca libre podría promover esta última ya que un banco que desee permanecer en el mercado debe asegurar la calidad y el poder adquisitivo de sus billetes: si sobre emitiera, su billete se depreciaría y no sería aceptado como medio de intercambio. En consecuencia, los bancos tendrían incentivos endógenos a evitar la sobre emisión o a deterirorar el respaldo metálico de sus billetes (Hayek 1976; White 1984a; Dowd 1988, 1994, 1996; Selgin 1988, 1994; Selgin and White 1994). Así, en la banca libre operaría una suerte de forma inversa de la Ley de Gresham y el "buen" dinero dominaría al "malo". Consistente con lo anterior, los defensores de la banca libre señalan que la desregulación no es fuente de inestabilidad o de crisis. Por el contrario, sería la regulación la verdadera causa. Otros autores han cuestionado esta mirada 
invocando la necesidad de regulación para la estabilidad del sistema, evitar la sobre emisión y un nivel indeterminado de precios (Taub 1985, Goodhart 1988, Dow 1996). Una serie de trabajos ha encontrado evidencia favorable a la tesis de estabilidad financiera al analizar las experiencias de banca libre de Estados Unidos (Rockoff 1974, 1985; Rolnick y Weber 1983; King 1983, Economopoulos 1988; Ifthekar y Dwyer Jr. 1994; Gorton 1996, 1999; Calomiris y Khan 1996) y de Escocia (White 1984b; Goodspeed 2016). En América Latina, una conclusión similar ha sido avanzada en el caso del Perú (Zegarra 2013b). En contrapartida, el análisis de experiencias como la de la crisis de 1893 en Australia ha llevado a la conclusión contraria (Hickson y Turner 2002, 2004).

Basado en fuentes primarias, en este trabajo examino la experiencia de banca libre en Chile entre 1860 y 1878 , momento en que una crisis bancaria pone fin a la convertibilidad de los billetes. El caso Chileno es de interés ya que la ley que origina el periodo es extremedamente cercana al caso "puro" planteado por la teoría. Así, al explicar la crisis de 1878, en principio el argumento de distorsiones legales no aplicaría. En cambio, sostengo que el sistema estuvo marcado por otra forma de distorsión: una estrecha y creciente relación entre el Estado y los bancos que, en los hechos, monetizaron los déficits fiscales. De esta forma, si bien el sistema Chileno estuvo, de jure, muy alineado con la ortodoxia de la banca libre, de facto, se apartó de su ideal. En particular, muestro que la crisis se asocia con un importante préstamo que se negocia desde fines de 1877. Apoyándome en los balances individuales y en el contrato de préstamo, argumento que éste fijaba indirectamente el precio de los billetes, desanclando al sistema en el aspecto disciplinador fundamental de la banca libre y por el cual el "buen" billete está llamado a dominar al "mal" billete. Sostengo que esto tenía como resultado esperado anticipaciones de sobre emisión y de depreciación de la moneda local, elementos que generaron incentivos a una crisis bancaria como la que ocurrió.

Una amplia literatura ha puesto de relieve la importancia de la economía política y de las interrelaciones entre banca y Estado (Hammond 1957; Sylla 2006; Haber 2008; Calomiris y Haber 2014). Sin embargo, en la literatura de banca libre el acento ha estado en las regulaciones formales y no en otras consideraciones de economía política con consecuencias para el funcionamiento del sistema. El estudio de la experiencia chilena hace una contribución relevante en esa dirección. Si bien el vínculo entre bancos y gobierno ha sido señalado por varios autores en el caso de Chile (Santelices 1893, Espinoza 1909, Ross 1910, Millar 1994, Ross 2003), el estudio formal de la estructura de incentivos y riesgos para la estabilidad financiera que involucraba el préstamo de 1877 no ha sido previamente abordado. Así, el trabajo hace una contribución original y proporciona una explicación complementaria necesaria para explicar el colapso de 1878. 
El resto del documento se estructura como sigue. En la segunda sección presento la evolución del sistema bancario chileno. Esto incluye una revisión de la Ley de Bancos de Emisión 1860 y de las primeras relaciones entre banca y gobierno. En la tercera sección doy cuenta del alcance de la crisis de 1878 y de las explicaciones más relevantes avanzadas por la literatura para dar cuenta del colapso. En la cuarta sección propongo una explicación adicional que se basa la estructura de incentivos del contrato de préstamo de 1877. A partir de ahí, analizo la racionalidad para el pánico bancario ocurrido en 1878. La quinta sección concluye.

\section{ORÍGENES Y DESARROLLO DE LA BANCA LIBRE EN CHILE}

Desde la Colonia, el sistema monetario chileno estaba basado en un esquema bimetálico de oro y plata. A partir de 1830, conforme el comercio interno y externo se desarrollan, empieza a producirse escasez de moneda divisionaria (Millar 1994). Esto incentivó la emergencia de medios de pago alternativos como monedas con menor contenido metálico, papel moneda de casas comerciales e incluso episodios en los que autoridades regionales emitieron vales al portador (Subercaseaux 1922; Millar 1994; Jeftanovic y Lüders 2007). Así, en la década de 1840, se instala el debate sobre la necesidad de establecer un sistema bancario. En 1845, el gobierno presenta un proyecto para crear un banco estatal, iniciativa que finalmente fue descartada. Tres años después se autoriza a un privado a crear el primer banco con facultad para emitir billetes: el Banco de Arcos y Cía. Sin embargo, en 1850 éste cierra debido a un fallo de la Corte Suprema que declara ilegal sus emisiones. Durante los 1850s, el aumento significativo de la actividad exportadora y del comercio hace que la escasez de circulante se agrave (Ross 2003) y las casas comerciales se transforman, de facto, en emisores de billetes (Jeftanovic y Lüders 2007). En paralelo se constituyen los primeros bancos comerciales formales del país: el Banco Bezanilla y Mac Clure (1854), el Banco Ossa (1856), el Banco de Valparaíso (1856) y el Banco de Chile (1859), los que, pese a no tener autorización, emiten billetes por montos acotados (Ossa 1888).

Lo anterior va generando consenso sobre la necesidad de reemplazar el esquema metálico por uno de billetes convertibles, debiéndo definir si éste debía ser asegurado por un banco estatal o bien por un sistema de banca libre. Es esta última visión la que se impuso: en 1860, Chile dicta la Ley de Bancos de Emisión cuyo autor intelectual fue el conomista francés Jean Gustave Courcelle-Seneuil ${ }^{1}$. La influencia de las ideas de la banca libre fueron tan fuertes que, durante la discusión parlamentaria de la ley, los círculos dirigentes mostraban una familiaridad notable con las experiencias

1 Uno de los principales exponentes de la Free-Banking School. En 1855 fue contratado como profesor de economía política en la Universidad de Chile y como asesor del Ministerio de Hacienda. Estuvo en Chile hasta 1863. 
de Escocia y Estados Unidos². La ley de 1860 era extremadamente liberal. El siguiente extracto del mensaje del Presidente Montt al anunciar la ley es ilustrativo:

(En Estados Unidos) la mayor parte de estas leyes imponen a los bancos odiosas restricciones. Algunas prohiben la creación de sucursales; otras determinan la naturaleza de las operaciones que los Bancos deben hacer, y no solo autorizan y prohíben tales o cuales operaciones, sino que avanzan hasta fijar el plazo de los efectos que pueden ser admitidos al descuento, [...] decidiendo algunas veces si los Bancos pagarán o no intereses por los depósitos que reciben y exijiendo la consignación de títulos de deuda pública como garantía del pago de los billetes. La Ley que os propongo carece de todas estas restricciones y deja un campo mucho más vasto a la libertad ${ }^{3}$.

Las principales caractéristicas de la Ley de 1860 eran las siguientes:

1. Cualquiera puede establecer un banco de emisión (Art. 1).

2. Los billetes son convertibles en todo momento en metálico (oro o plata) a la vista y al portador (Arts. 26 y 27).

3. Los bancos no están obligados a mantener un porcentaje mínimo de reservas metálicas pero no pueden emitir billetes por una suma superior al 150\% de su capital pagado (Art. 29). Este capital debe estar constituido por moneda de curso legal, por reservas metálicas o por obligaciones menores a seis meses de personas notoriamente solventes (Art. 6).

4. El director de un banco por acciones es solidariamente responsable de las obligaciones contraídas por el banco durante su dirección, debiendo mantener acciones del banco libre de toda obligación por lo que resulte menor entre un 10\% del capital del banco o $\$ 40.000$ (Art.9). A su vez, los préstamos a los directores o administradores del banco deben ser presentados en una cuenta especial del balance (Art. 10).

5. Los bancos deben publicar balances mensuales auditados por el Ministerio de Hacienda (Arts. 8 y 30). Estos eran difundidos por la prensa de la época, siéndo de dominio público ${ }^{4}$.

\subsection{Primeros bancos y desarrollo del sistema}

Pese al liberalismo de la ley de 1860, hasta 1865 solo el Banco de Chile emitió billetes al alero de esa ley y por montos muy reducidos. En septiembre

\footnotetext{
${ }^{2}$ Ver las intervenciones de los diputados Varas (30/6/1859) y Gandarillas (02/07/1859). En Sesiones de la Cámara de Diputados (en adelante SCD) 1859: 57-58 y 62.

3 Citado en Ross (1886:43).

${ }^{4}$ Se trata de una provisión fundamental: al permitir monitorear de manera contínua la situación financiera de los bancos, contribuía a que los agentes diferenciaran la calidad de los distintos billetes.
} 
de 1865, Chile declara la guerra a España y se autoriza al Banco Nacional de Chile (sucesor del Banco de Chile) a emitir, hasta enero de 1866, \$1.500.000 en billetes inconvertibles y recibibles a su valor nominal contra todo pago en favor del Estado. Detrás de esta concesión se invoca el agravamiento de la escasez de circulante que traería la guerra y la necesidad de alentar el comercio ${ }^{5}$. En búsqueda de nuevos fondos, en julio de 1866 el gobierno recurre al sistema bancario y contrata un préstamo por $\$ 4.539 .000$ con los bancos Nacional, Mac Clure (sucesor del Banco Bezanilla y Mac Clure), Valparaíso, Ossa y el banco Edwards, fundado ese mismo año. Para alentarlos a participar del préstamo, el Estado les permite emitir billetes, por hasta el monto prestado, con el "privilegio exclusivo de ser recibidos en todas las oficinas fiscales por su valor nominal y como moneda corriente por el término de 22 años". Además, garantiza que cualquier modificación a la ley de 1860 no les sería aplicable y que los bancos podían renunciar al privilegio en cualquier momento.

Los incentivos para suscribir el acuerdo y comenzar a emitir billetes eran claros: la recepción a su valor nominal contra todo pago en favor del Estado facilitaba su circulación. Pero, por la misma razón, conceptualmente el mecanismo disciplinador de un sistema de banca libre se ve negativamente afectado ya que el banco podía ser más laxo en su preocupación por el respaldo metálico de sus billetes para "convencer" al público de recibirlos. En otras palabras, la calidad del billete pasa a ser menos relevante. Si bien en un contexto de contracción monetaria el acuerdo de 1866 no generó consecuencias adversas, es un precedente valioso para entender la estrecha relación que existirá entre el Estado y los bancos en los años subsecuentes y los alcances de un nuevo préstamo en 1877/78 con montos de emisión privilegiada sustancialmente mayores.

Durante los 1870s, se produce una significativa expansión bancaria derivada de un contexto económico favorable (la economía crece al 7\% anual en 1872 y 1873) e influjos provenientes de emisiones soberanas por 4,4 millones de libras entre 1870 y 1875 (Sicotte et al. 2009). Así, durante esta década se crean nuevos bancos (Tabla 1), existiendo 11 instituciones en 1877. Los depósitos y colocaciones más que se duplican entre fines de los 1860s y la primera mitad de los 1870s (Figura 1), mientras que la cobertura territorial se expande gracias a un gran incremento en el número de sucursales, que suben de 4 en 1866, a 23 en 1873 y 37 en 1878 .

La expansión de la economía significó que el techo de emisión privilegiada de 1866 se fue tornando limitativo. En 1872 el Banco de Valparaíso renuncia a su privilegio debido a que "la emisión privilegiada se había transformado en una restricción que afectaba sus intereses" ${ }^{\prime \prime}$ y cede su derecho al Banco Edwards en un valor que estimamos en 20\% del monto

5 Intervención, Ministro de Hacienda en el Senado. Sesión Oridinaria del Senado (en adelante SOS), 23/09/1865.

${ }^{6}$ Memoria del Ministerio de Hacienda, (1876:128). 
TABLA 1

BANCOS DE EMISIÓN CREADOS/CERRADOS EN CHILE 1860-1878

\begin{tabular}{|l|l|c|c|}
\hline & Banco & $\begin{array}{c}\text { Fundación/ } \\
\text { Cierre }\end{array}$ & $\begin{array}{c}\text { Primera emisión de } \\
\text { billetes }\end{array}$ \\
\hline 1 & Nacional de Chile & $1865^{*}$ & 1865 \\
\hline 2 & Mac-Clure y Cia $(* *)$ & $1854 * *$ & 1866 \\
\hline 2 & Matte, Mac Clure y Cía (***) & 1872 & 1872 \\
\hline 2 & Matte y Cía (***) & 1876 & 1876 \\
\hline 3 & Ossa y Cía & 1856 & 1866 \\
\hline 4 & Valparaíso & 1856 & 1866 \\
\hline 5 & Edwards y Cía & 1866 & 1866 \\
\hline 6 & Agrícola & 1869 & 1869 \\
\hline 7 & Mobiliario & 1870 & 1870 \\
\hline 8 & Concepción & 1871 & 1872 \\
\hline 9 & Alianza (***) & 1872 & 1872 \\
\hline 10 & de la Unión & 1874 & 1876 \\
\hline 11 & Consolidado & 1876 & 1877 \\
\hline 12 & Montenegro y Cía & $1869 / 1874$ & 1869 \\
\hline 13 & del Sur & $1870 / 1871$ & 1870 \\
\hline 14 & del Pobre & $1871 / 1877$ & 1874 \\
\hline 15 & Sud Americano (1) & $1872 / 1873$ & 1872 \\
\hline & & & \\
\hline
\end{tabular}

Fuente: Autor. (*) Sucede al Banco de Chile fundado en 1859. (**) Sucede al Banco Bezanilla y Mac Clure fundado en 1854. (***) Mismo banco pero que cambia de nombre. $(* * * *)$ Banco subsidiario del Nacional. (1) en 1873 se fusiona con el Banco de Valparaíso.

de emisión privilegiada traspasado. De igual manera, los bancos Ossa (1871) y Matte y Mac Clure (1875, sucesor del Banco Mac Clure) cedieron sus derechos al Banco Nacional, recibiendo por ello un pago que estimamos en un $16 \%$ del derecho de emisión. El Banco Nacional también se veía limitado por el techo de 1866. Al cierre de 1871, éste tenía una cantidad de billetes privilegiados en circulación que rozaba el máximo permitido de $\$ 2,8$ millones. Para sortear esta limitación, en 1872 crea un banco filial, el Banco Alianza, cuyo capital estaba conformado casi en su totalidad por acciones del Nacional (Santelices 1893). De acuerdo a un observador 


\section{FIGURA 1}

DEPÓSITOS, COLOCACIONES Y BILLETES EN CIRCULACIÓN (\$ CORRIENTES)

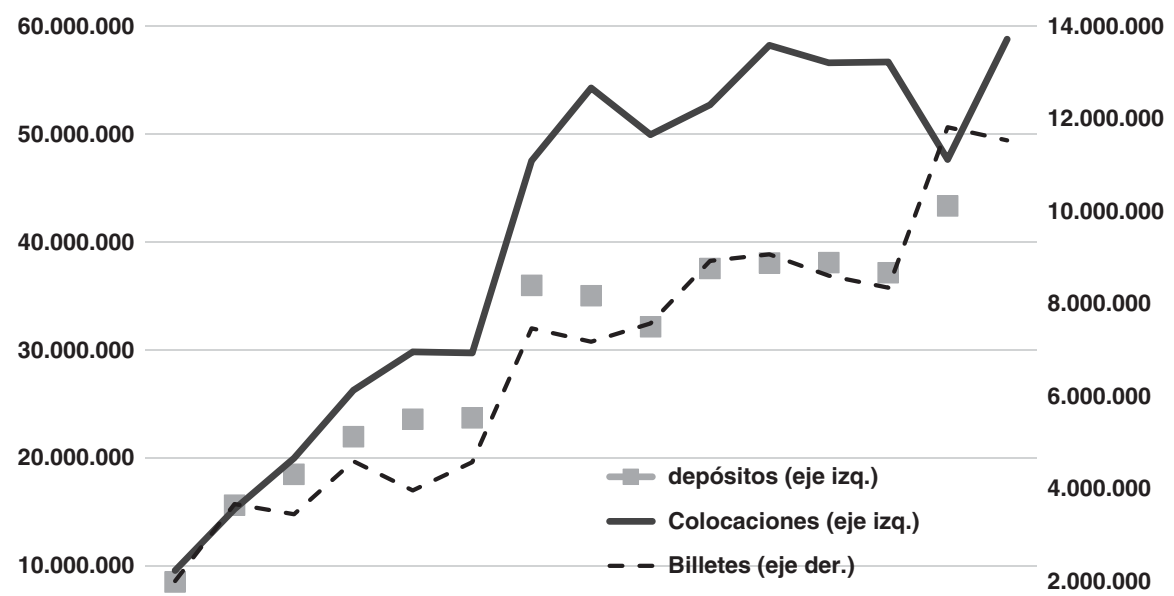

0 ¿

Fuente: Calculado a partir de los balances individuales.

de la época "el banco fue fundado para burlar la limitación de la emisión del Nacional"7.

Pese a lo limitativo del techo de emisión de 1866, la emisión privilegiada confería una clara ventaja para la circulación de ese tipo de billetes. De acuerdo al diario El Telégrafo (25/02/1878): "No hay duda que los billetes privilegiados por el Estado tenían mucha más aceptación a lo largo del país que los simples billetes convertibles de los otros bancos [...] en muchas localidades del país sólo los billetes de los bancos privilegiados eran recibidos incondicionalmente". Conceptualmente, la mayor facilidad de circulación de los billetes privilegiados debía traducirse en una menor cobertura metálica. Los balances tienden a confirmar esta predicción. Antes de renunciar a su privilegio, el Banco de Valparaíso tenía una razón entre metálico y billetes más depósitos de 8,9\%, cifra que, entre 1872 y 1878 (luego de la renuncia) sube a 14,7\%. En el mismo periodo, este indicador para los Bancos Edwards y Nacional (privilegiados) era de 6,8\% y 10,6\%, respectivamente. Una conclusión similar se obtiene si comparamos los billetes en circulación como proporción del capital. Entre 1872 y 1877, el valor promedio para

7 El Ferrocarril, 06/02/1878. El firmante, aunque anónimo, sería el diputado Zorobabel Rodríguez, discípulo de Courcelle-Seneuil. 
los Bancos Nacional y Edwards fue de 73,5\% y 104,4\%, respectivamente. En el caso de los bancos de Valparaíso, Ossa y Matte y Mac Clure, luego de renunciar a su privilegio, este ratio llegaba al 29,1\%,27,8\% y $43 \%$, respectivamente.

En 1877 los Bancos Edwards y Nacional buscan extender el ámbito de su emisión privilegiada y reclaman al Gobierno incluir al correo, al telégrafo y los ferrocarriles como parte de las oficinas fiscales donde sus billetes debían tener recepción exclusiva. En julio de 1877 el Ministro del Interior accede a la solicitud, provocando el reclamo de los otros bancos y un fuerte debate en la prensa. Un observador de la epóca señalaba ${ }^{8}$ que el Nacional: "ideó la peregrina pretensión de que el privilegio de sus billetes para ser los únicamente recibidos en arcas fiscales, se hiciese extensivo a todas las demás oficinas nacionales. [...] la complacencia de un Ministro estuvo a la altura de las pretensiones del banco".

\subsection{Los bancos dominantes}

Pese a la emergencia de nuevos bancos durante los 1870s, tres de ellos concentraban cerca del $80 \%$ del total de depósitos y billetes (Figura 2). El Banco Nacional era el actor dominante con un 50\% de participación de mercado, seguido de los bancos de Valparaíso y Edwards. Los dos primeros eran sociedades anónimas listadas en bolsa, mientras que el Banco Edwards era una sociedad de responsabilidad ilimitada. Su dueño, Agustín Edwards Ossandón, con una fortuna estimada en casi 5\% del PIB, era el hombre más rico de Chile ${ }^{9}$. El Banco Nacional era también el más rentable (Figura 3). Durante los 1870s, éste obtiene un retorno promedio anual sobre su capital de $17 \%$, cifra superior a la del Banco de Valparaíso (10\%), a la del banco Edwards (14\%) y a la de los restantes bancos $(13 \%)^{10}$.

Luego de renunciar a su privilegio en 1872, el Banco de Valparaíso sigue una agresiva estrategia para competirle al Nacional. Entre 1872 y 1874, aumenta su capital desde $\$ 2.400 .000$ a $\$ 6.150 .000$ (el Nacional lo aumenta desde \$2.500.000 a \$3.750.000). Si hasta 1872 el Banco Nacional era el único banco que tenía sucursales (cinco en total) en diferentes puntos del país, en 1873, el Banco de Valparaíso había creado cuatro y en 1878, estaba presente en doce ciudades contra nueve del Nacional. Hasta 1876, el Banco de Valparaíso fue exitoso en ganar en participación de mercado a nivel de billetes. No así en depósitos, en contraste con el aumento que logra el Nacional.

8 El Ferrocarril, 13/02/1878.

9 Nazer (2000: 370).

10 De acuerdo a Calomiris y Kahn (1996, Tabla 9) y Rockoff (1974, Tabla 2), estas tasas de retorno, particularmente las del Nacional, son relativamente altas comparadas con las de la experiencia de banca libre en Estados Unidos (1837-61) en los estados de Nueva York y Masschussetts (8\%), aunque, con excepción del Nacional, no en relación a Filadelfia (11\%). Salvo por el caso del Nacional, tampoco son significativamente mayores a las cifras puntuales $(12,5 \%)$ reportadas por Goodspeed (2016, p. 22) durante la Banca Libre en Escocia (1716-1844) o a las cifras de Checkland (1975, Tabla 45), para los años inmediatamente posteriores a la banca libre en ese país. 
FIGURA 2

DEPÓSITOS Y BILLETES EN CIRCULACIÓN: PARTICIPACIÓN DE MERCADO DE LOS TRES PRINCIPALES BANCOS

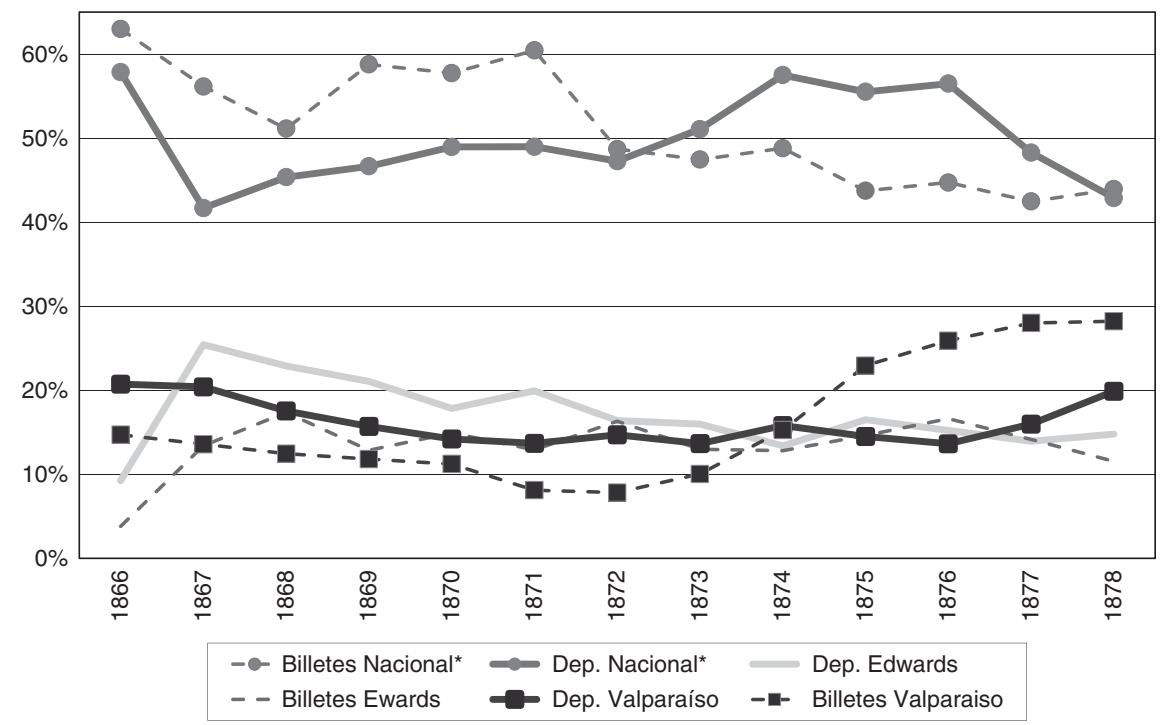

Fuente: Calculado a partir de los balances individuales. (*) Incluye el Banco Alianza, filial del Nacional.

¿Por qué el Nacional se mostraba invulnerable a los esfuerzos de su más agresivo competidor? ¿Por qué crece en depósitos durante los 1870s? Una parte importante de la explicación es que recibió una serie de privilegios adicionales que lo transformaronen un cuasi banco estatal. Un informe enviado en 1876 por el Nacional al Ministerio de Hacienda, señalaba que ${ }^{11}$ :

La relación entre el banco y los intereses fiscales se ha seguido intensificando luego de la apertura de líneas de crédito, tanto en Chile como en Europa, para el seguimiento y la transferencia de fondos entres las distintas agencias del Tesoro y entre los mercados europeos y dentro de la República.

El pasaje ilustra la particular relación entre el Nacional y el Estado desde fines de los 1860s. Ya en 1869, una ley permite al fisco abrir en el Banco una línea de crédito por $\$ 1 \mathrm{MM}$ y otro contrato le da la exclusividad en la recepción de depósitos del Tesoro. En 1873 el fisco amplía a \$ 3,25 MM la línea de crédito y el Banco recibe la exclusividad para la gestión de los fondos

11 Memoria del Ministerio de Hacienda, (1876:120). 
FIGURA 3

UTILIDAD ANUAL/CAPITAL TOTAL (*)

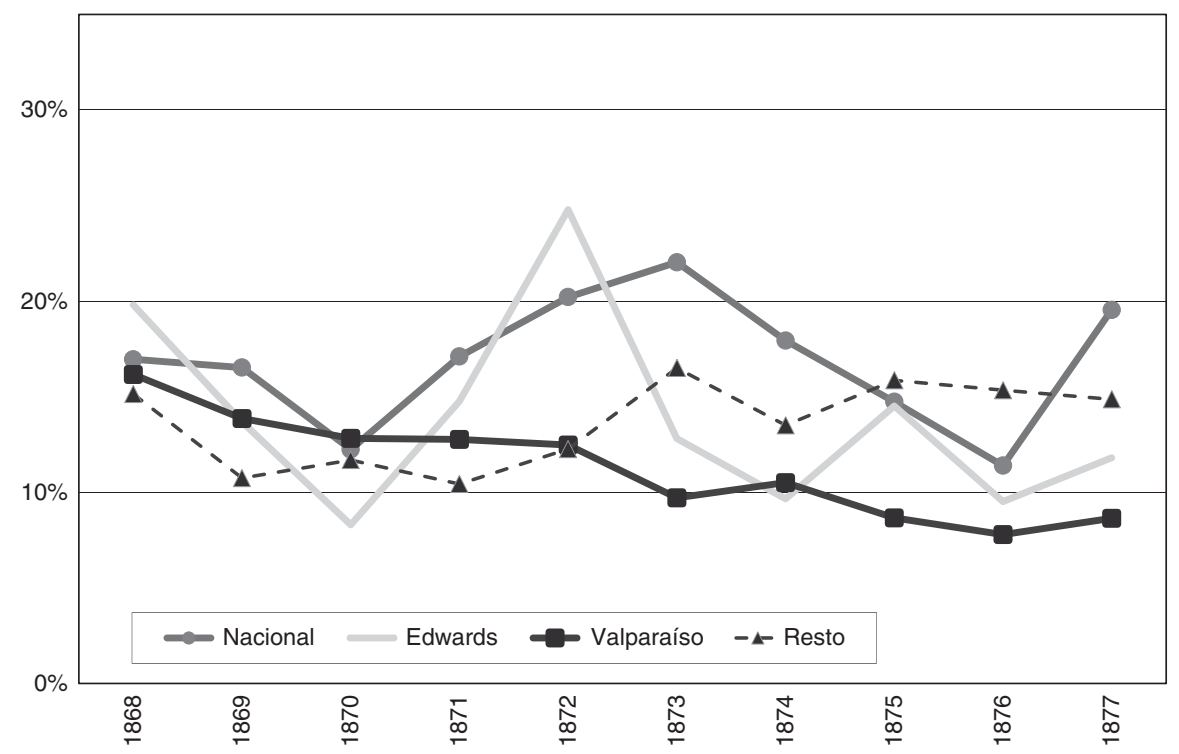

Fuente: Calculado a partir de los balances individuales. (*) El capital total incluye el capital pagado, el fondo de reserva y el fondo de dividendos.

del Tesoro por un período de 26 años. El Gobierno le confiere también la responsabilidad para la emisión de bonos en Londres por un valor nominal de $£ 2.140 .000 \mathrm{y}$, posteriormente, le da derechos exclusivos para realizar todas las operaciones de divisas, gestión de la deuda externa y cualquier negocio o transferencia realizada con otros países. La señal era clara: el banco se había transformado en una suerte de banco estatal. Según el banquero Nicomedes Ossa ${ }^{12}$, los contratos suscritos entre el Banco Nacional y el Gobierno lo habían transformado en:

[...] una especie de Tesorería General del Estado y en un organismo pagador la deuda externa del Estado. (...) El Banco Nacional, que ya era considerado por el público ignorante como un banco estatal, ganaba en materia de crédito, veía entrar en sus arcas depósitos en grandes cantidades, y ampliaba sus operaciones de manera poco prudente. ${ }^{13}$

12 Se trata de uno de los fundadores del Banco Ossa y Cía. y también diputado (1852-55/1864-76).

13 Ossa (1888:110-111). 


\section{LA CRISIS BANCARIA DE 1878}

Luego de casi dos décadas de desarrollo bancario, en 1876 el Ministro de Hacienda se vanagloriaba de la ininterrumpida convertibilidad metálica de la banca chilena ${ }^{14}$. Pero esa confianza se derrumbaría dos años más tarde. Durante el primer semestre de 1878 se produce una crisis bancaria que termina con la suspesión de la convertibilidad y el establecimiento del curso forzoso.

\subsection{La crisis y los bancos afectados}

Las primeras señales de inquietud se producen a fines de 1877 con la quiebra de la casa comercial Thomas que, si bien no era un banco formal, efectuaba operaciones de crédito vinculadas a los negocios de ingleses en Valparaíso (Aranguiz 1993). El 21 de enero de 1878 quiebra el pequeño Banco del Pobre $(0,6 \%$ de participación de mercado). Ese mismo día se produce una conversión masiva de billetes del Banco de la Unión (0,8\% de participación de mercado) que lo llevó al borde de la quiebra. De acuerdo al Diario el Ferrocarril (13/2/1878), ello habría ocurrido debido a la súbita no aceptación de sus billetes por parte del Banco Nacional. De hecho, el verdadero problema se produce a nivel del Banco Nacional cuya importancia era sistémica. Desde octubre de 1877 se observa una baja significtiva en la cotización de sus acciones, perdiendo un $24 \%$ de su valor a febrero de 1878 y un $45 \%$ a junio. Los balances mensuales del banco, que se siguieron publicando de forma ininterrumpida en la prensa y por lo tanto eran de dominio público, indican que, a partir de fines de 1877, éste experimenta una baja significativa de sus reservas metálicas y un retiro importante de depósitos (Figura 4). Entre enero y julio éstos últimos caen en $\$ 4$ MM (22\% del total) y sus reservas metálicas descienden desde $\$ 1.721 .000$ a $\$ 570.000$. Consecuentemente, su ratio de cobertura metálica disminuye desde un $15 \%$ en octubre de 1877 a un 5\% en junio y apenas a un 3,3\% en julio, quedando al borde de la quiebra. Refiriéndose al Nacional, el semanario dirigido a inversionistas extranjeros The Chilean Times señalaba (27/07/78): "It is no secret that of late a heavy run has been made on at least one important institution, which if continued must have resulted in its suspension, and this would have undoubtedly brought about a regular panic and a general crash".

Los bancos de Valparaíso, Concepción y Agrícola exhiben una caída significativa de su ratio de cobertura metálica a partir del segundo trimestre de 1878 (Figura 5). El caso del Banco de Valparaíso es relevante por su importancia (20\% del mercado de depósitos). Pese a que no se observa un patrón de retiro masivo de depósitos, el banco sufre una cuantiosa disminución de sus reservas metálicas por casi $\$ 700.000$ entre abril y junio de 1878 (50\% de sus reservas). Así, su cobertura metálica sobre depósitos y billetes baja desde un 15\% a fines de 1877 a un 7\% en junio de 1878. Los balances

${ }^{14}$ Memoria del Ministerio de Hacienda, (1876: 38-39). 
FIGURA 4

BANCO NACIONAL: DEPÓSITOS Y METÁLICO (\$ CORRIENTES)

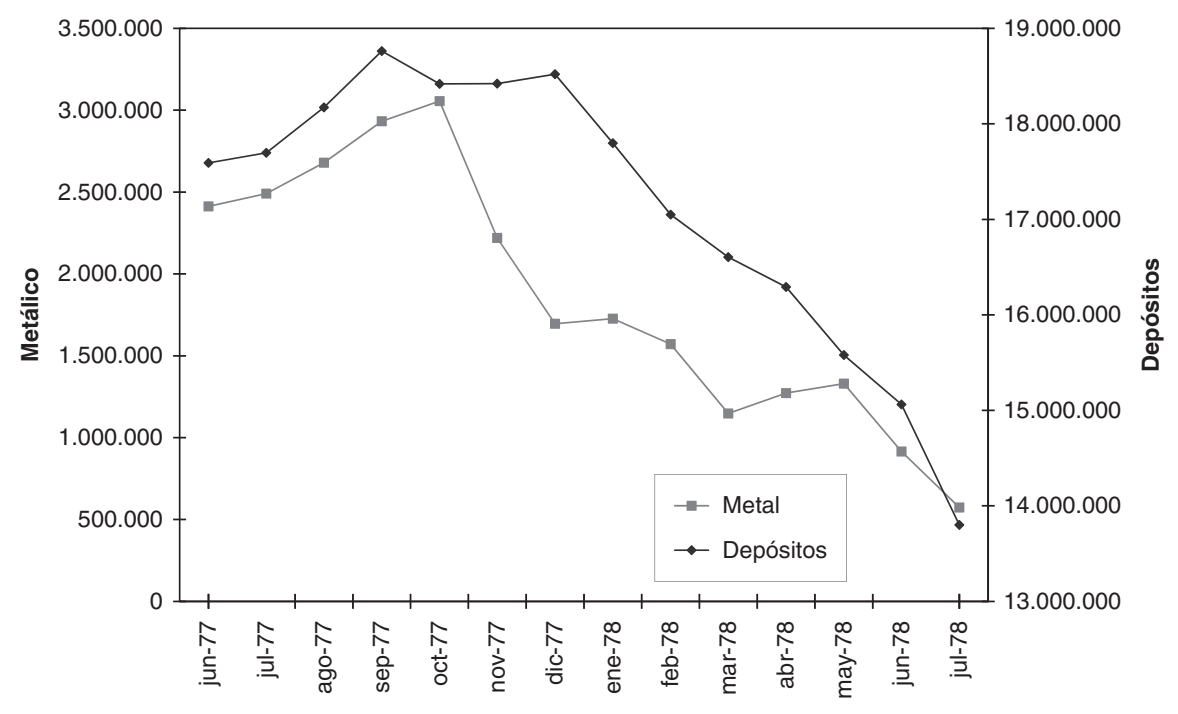

Fuente: Calculado a partir de los balances individuales.

sugieren que la disminución de metálico pudo deberse a las dificultades que experimentaba el Nacional. En efecto, desde fines de 1877 y hasta junio de 1878, la cuenta de la caja del Nacional "cheques y billetes de otros bancos" cae en \$700.000. Dado el tamaño del Banco de Valparaíso y el hecho que solo éste y el Nacional tenían sucursales a lo largo del país, es plausible suponer que una fracción relevante de este monto fue convertido en el Banco de Valparaíso.

El caso del tercer banco en importancia, el Banco Edwards (15\% del mercado), fue distinto. Sus depósitos se mantienen relativamente estables y no se observa un deterioro de su cobertura metálica. El mismo patrón (Figura 6) se aprecia en los casos de los bancos Ossa y Matte ${ }^{15}$ (7\% del mercado en conjunto). Una posible explicación es la condición de sociedad de responsabilidad ilimitada de estos tres bancos. En efecto, la responsabilidad ilimitada puede ser un disuasivo a una corrida y contribuir a la estabilidad (Hickson and Turner 2004; Goodspeed 2016). De igual forma favorece un comportamiento más responsable en la toma de riesgos (Grossman y Imai 2013), aunque también puede representar una barrera a la entrada (Carr y Mathewson 1988). Los atributos de mayor solvencia de tal esquema societario eran conocidos y valorados en la comunidad de negocios

15 Sucesor del Banco Matte y Mac Clure. 
FIGURA 5

RESERVAS METÁLICAS/BILLETES Y DEPÓSITOS

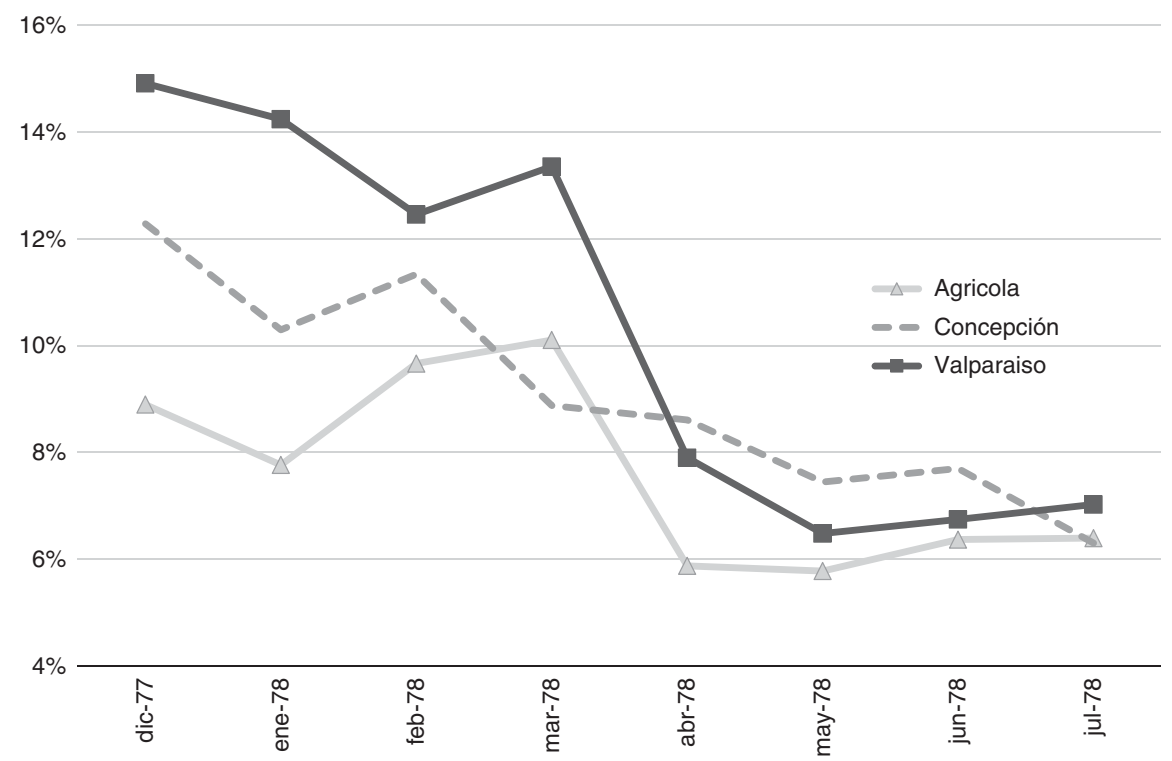

Fuente: Calculado a partir de los balances individuales.

de Chile $^{16}$, al tiempo que el propio Banco Edwards se encargaba de publicitar su caso en la prensa ${ }^{17}$. Si bien la ley de 1860 hacía solidariamente responsables a los directores de bancos constituidos como sociedades anónimas y los obligaba a constituir garantías a tal efecto, hay razones para pensar que esta provisión no era tan robusta. Una revisión exhaustiva del listado de accionistas revela que las garantías que los directores debían constituir estaban muy lejos de las que mandataba la ley ${ }^{18}$. De esta forma, la

16 Ver por ejemplo la correspondencia entre S. Williamson y A. Balfour, socios de Williamson, Balfour and Co. una de las casas comerciales más importantes de Valparaíso (citado en J. Mayo, 1987).

17 Por ejemplo, en enero de 1878, cuando fallece el fundador del Banco, se publica un inserto en la prensa poniéndo especial enfásis en que la sucesión del banco mantendría su condición de sociedad de responsabilidad ilimitada (El Ferrocarril 10/01/1878).

18 Por ejemplo, en 1865, 1873 y 1878 la participación accionaria agregada de los directores del Banco Nacional era de 11,5\%, 6,3\% y 7,2\%, respectivamente con un promedio por director sobre el capital pagado de $\$ 21.000$, $\$ 16.930$ y $\$ 24.130$ en cada caso. En las mismas fechas, la participación total de los directores del Banco de Valaparaíso era de 6\%, 10\% y 9,6\%, respectivamente, con promedios por director sobre el capital pagado de $\$ 4.300, \$ 22.600$ y $\$ 31.070$, respectivamente. Para los bancos Agrícola y Concepción, la participación agregada de sus directores en 1878 era de 11,4\% y $15,2 \%$, respectivamente, con un promedio por director sobre el capital pagado equivalente a 
FIGURA 6

RESERVAS METÁLICAS/BILLETES Y DEPÓSITOS

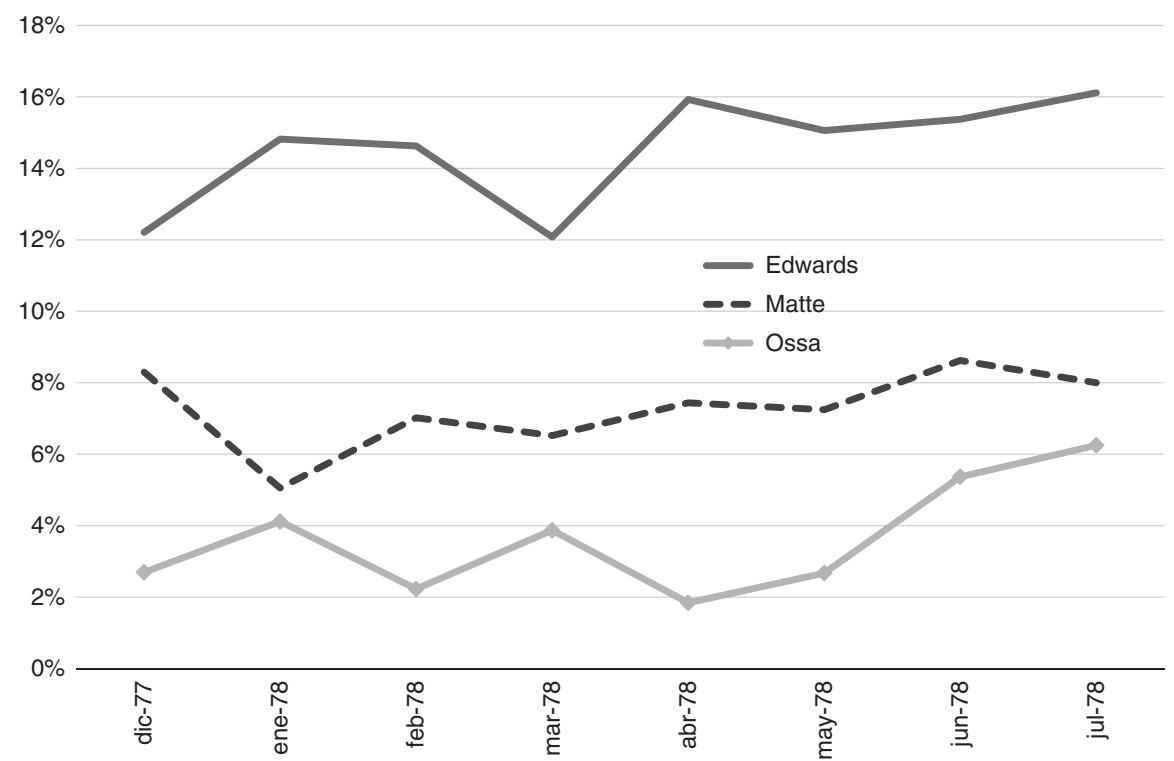

Fuente: Calculado a partir de los balances individuales.

figura de responsabilidad solidaria de los bancos por acciones no era del todo equiparable a la de responsabilidad ilimitada, máxime teniendo en cuenta el conocido y amplio patrimonio de los dueños de estos últimos, particularmente en el caso de los Bancos Edwards y Ossa ${ }^{19}$.

\subsection{Principales explicaciones de la crisis}

Si bien el sistema banacario Chileno nunca fue realmente de banca libre en el sentido ortodoxo del término, diversos autores han señalado que una razón fundamental de la crisis fue el liberalismo de la Ley de Bancos. Según Espinoza (1909), "Chile fue precipitado por los bancos de emisión a todos los desastres del curzo forzozo [...] como consecuencia de las liberalidades extremas de la ley de 1860". La ley habría llevado a los bancos a un

\footnotetext{
(footnote continued)

$\$ 24.840$ y $\$ 3.800$, en cada caso. Como se aprecia, en todas las situaciones la garantía accionaria promedio estaba por debajo del monto mínimo de $\$ 40.000$ definido por la Ley de 1860 .

19 José Santos Ossa, minero y dueño del Banco Ossa, era considerado también como uno de los hombres más ricos de Chile.
} 
comportamiento irresponsable (Fuentealba 1945), incluyendo una expansión desmedida del crédito (incluso con características especulativas) y de la emisión sin el debido respaldo (Ross 2003). Esta tésis puede cobrar particular relevancia ante problemas de agente-principal entre accionistas y directores que pueden superponer su beneficio al de los primeros. Sin embargo, en el caso chileno no es claro que esto haya sido así. Si bien las garantías que, según la Ley, debían enterar los directores de bancos constituidos como sociedades anónimas no fueron respetadas a plenitud, no deja de ser cierto que la mayoría de los directores eran accionistas de los bancos y que su participación conjunta era relevante. Por ejemplo, en 1878, los directores de los bancos Nacional, Valparaíso, Agrícola y Concepción (principales bancos constituidos como sociedades anónimas) tenían, respectivamente, $7,2 \%, 9,6 \%, 11,4 \%$ y $15,2 \%$ del capital de sus bancos. Así, los intereses de accionistas y directores parecen haber estado razonablemente alineados. Por otra parte, los balances no muestran un patrón inusual en materia de crecimiento del crédito o de la emisión en los albores de la crisis. Si bien las colocaciones bancarias se duplican (Figura 1) entre 1870 y 1874, a partir de 1874 este crecimiento se detiene. A su vez, del incremento de las colocaciones producido entre 1870 y 1874 y no explicado por un incremento de depósitos, un $75 \%$ estuvo financiado a través de aumentos de capital y un $25 \%$ por expansión de la emisión. Se ha señalado también (Ross 1893, Espinoza 1909; Fetter 1931), que el comportamiento oportunista de los banqueros se expresó a través de un incremento de los dividendos y de los préstamos a directores. Sin embargo, en los balances no se aprecia un incremento inusual de la tasa de dividendos semestral previo a la crisis, ni una diferencia significativa con las tasas de los años posteriores (Figura 7). Como fracción de las utilidades, los dividendos repartidos tampoco muestran un comportamiento atípico. Entre 1876 y el primer semestre de 1878 el dividendo promedio semestral fue un $95 \%$ de la utilidad semestral, en los casos de los bancos Nacional y de Valparaíso y de $90 \%$ y $80 \%$, respectivamente, para los bancos Agrícola y Concepción. Ninguna de estas cifras difiere significativamente del promedio para los años previos a 1876.

A nivel de préstamos a directores tampoco hay un patrón de comportamiento oportunista claro antes de la crisis (Figura 8). Como fracción de las colocaciones totales, estos préstamos se incrementan moderadamente en el caso del Nacional (58\% del total de préstamos a directores de la industria) durante el primer semestre de 1878 pero quedan por debajo del promedio de la primera mitad de los 1870s. Además el aumento de este cuociente se explica fundamentalmente por una caída en las colocaciones más que por un incremento de los montos prestados a directores. En el caso del Banco de Valparaíso (28\% del total de préstamos a directores), esta fracción es estable desde fines de 1876. Para los restantes bancos que registran préstamos a sus directores, se observa un alza moderada durante el primer semestre de 1878. 
FIGURA 7

TASA DE DIVIDENDOS SEMESTRALES (\% DEL CAPITAL TOTAL*)

12

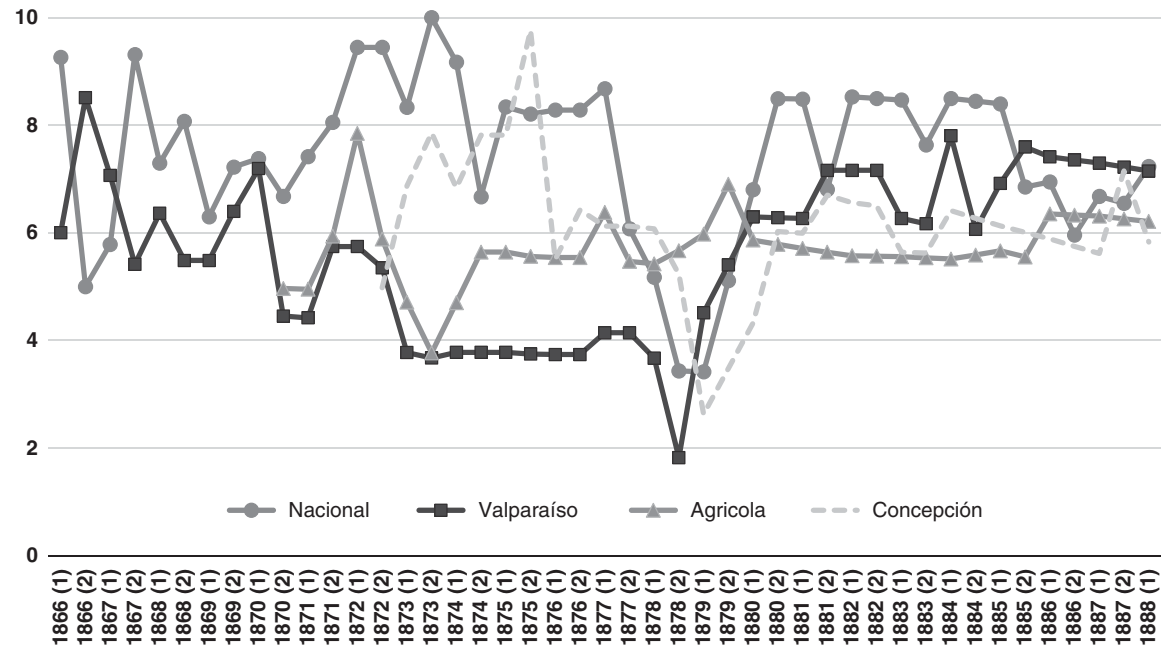

Fuente: Calculado a partir de Santelices (1893) para los dividendos como fracción del capital pagado y balances de los bancos para el capital total. (*) El capital total incluye el capital pagado, el fondo de reserva y el fondo de dividendos. (1) y (2) señalan el primer y segundo semestre, respectivamente.

Con todo, a nivel del sistema, este indicador se mantiene bastante estable desde $1876^{20}$.

Una segunda explicación relevante de la crisis se asocia al impacto de la depresión mundial de los años 1870s (Sater 1979; Subercaseaux 1922, Millar 1994; Hirschman 1963). De acuerdo a Díaz et al. (2010), luego de una expansión del PIB de 8,3\% en 1875, éste se contrae 1\% y 3,2\% en 1876 y 1877, respectivamente. A su vez, en 1877, la producción agrícola y minera retroceden $10,7 \%$ y 10,2\%, en cada caso. El shock externo también produjo un deterioro relevante de las cuentas externas pero no a niveles de generar una crisis de balanza de pagos como se ha invocado (Llona 2000). En 1876 los términos de intercambio alcanzan el peak de la década y sufren una caída de $8 \%$ en 1877, aunque se mantienen en los niveles promedio del decenio. Entre 1875 y 1877 la balanza comercial y la cuenta corriente muestran,

20 Es del caso notar que ninguno de los bancos constituidos como sociedades de responsabilidad ilimitada (Edwards, Matte y Ossa) efectuaban préstamos a sus directores. 
FIGURA 8

COLOCACIONES CON DIRECTORES (\% TOTAL DE COLOCACIONES)

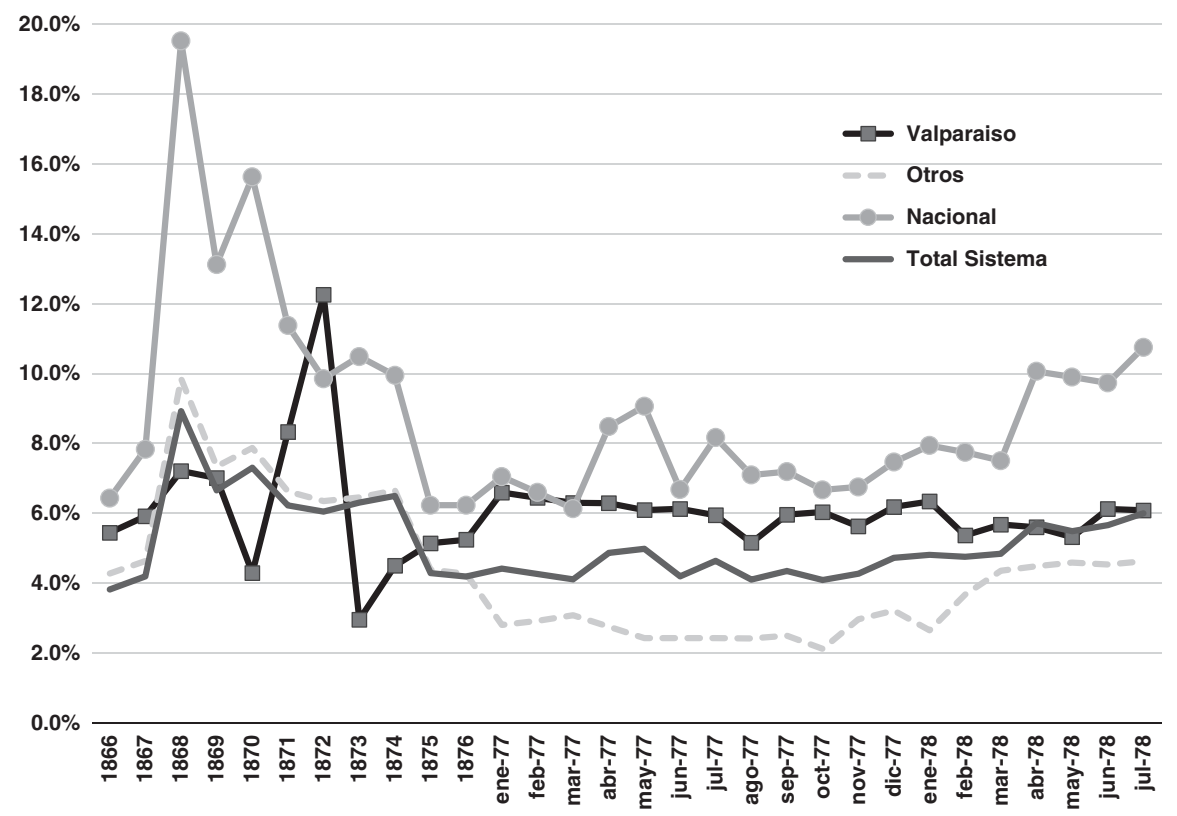

Fuente: Calculado a partir de los balances individuales.

en relación al $\mathrm{PIB}$, saldos anuales de $-1,2 \%$ y $-1,6 \%$, respectivamente, comparados con valores promedio de $+0,5 \%$ y $-0,3 \%$ entre 1870 y 1874 , respectivamente. No cabe duda que un shock externo como el descrito puede haber jugado un papel importante, no solo en la actividad económica sino también en las finanzas públicas, como analizaremos enseguida. Con todo, es interesante notar que los balances de los bancos no muestran un empeoramiento en sus principales razones de cobertura, sino que incluso una ligera mejoría entre 1875 y fines de 1877 (Figura 9). Todo lo anterior lleva a pensar que detrás de la crisis debe existir una explicación adicional, tal como lo plantearemos a continuación.

\section{EXPLICANDO LA CRISIS: EL PRÉSTAMO DE 1877-1878}

En plena crisis bancaria, el Diario the Chilean Times (27/07/1878) señalaba: "The present difficulties of the banks are in great measure due to the government [...]. Deficit after deficit has been covered by loans thus obtained instead of being provided for by additional taxation". El pasaje es ilustrativo de los severos 


\section{FIGURA 9}

RAZONES DE COBERTURA SOBRE OBLIGACIONES TOTALES (BILLETES + DEPÓSITOS)

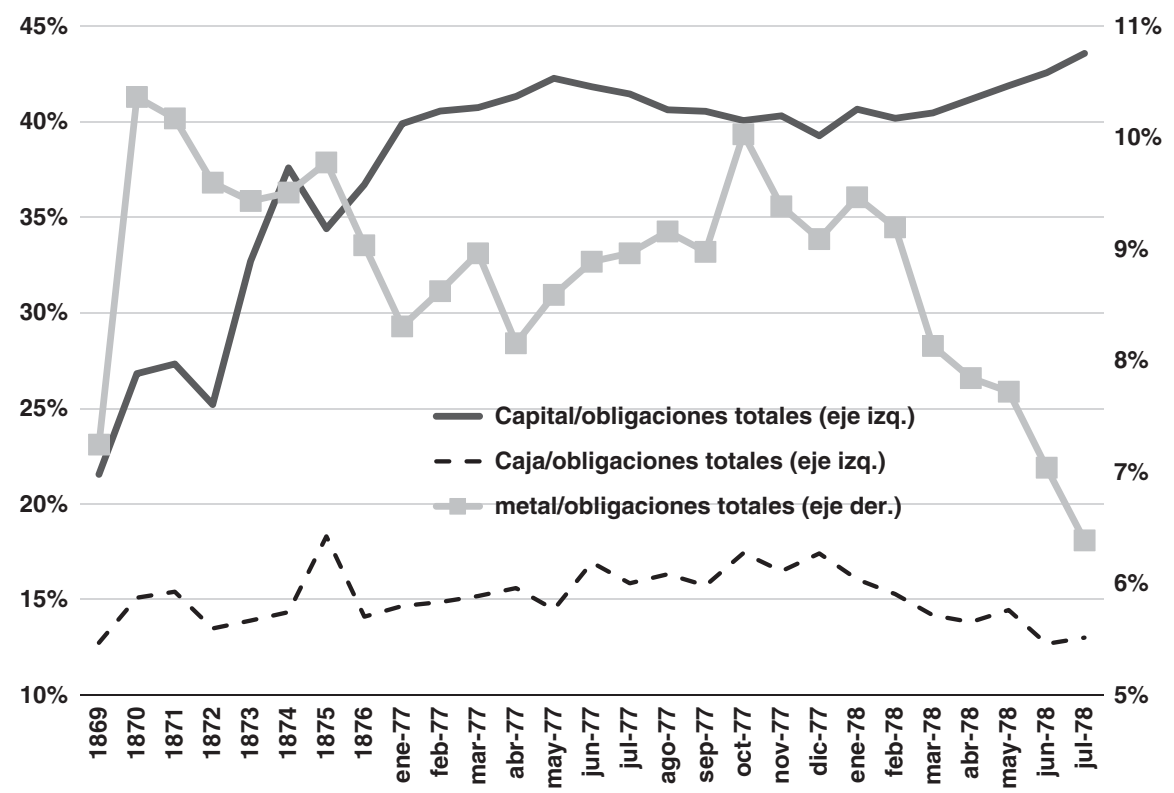

Fuente: Calculado a partir de los balances individuales.

imbalaces fiscales de la segunda mitad de los 1870 s y de como su financiamiento a través de endeudamiento, particularmente bancario, pudo haber contribuido a la crisis. Sostengo que la monetización del déficit por los bancos a cambio de la recepción de privilegios de emisión constituye una explicación adicional y fundamental para entender el pánico de 1878. Aunque diversos autores han aludido a este préstamo (Ross 1893; Espinoza 1909; Millar 1994; Ross 2003), lo han hecho como una forma de explicar el salvataje a los bancos y no como un elemento gatillador de la crisis. Mi argumento es diferente y se basa en un aspecto no abordado previamente: el análisis de la estructura de incentivos del préstamo y como ésta era incompatible con la mantención de un sistema de banca libre basado en la convertibilidad metálica. Postulo que las condiciones del préstamo incitaban a la sobre emisión, a un deterioro de la calidad de los billetes y, en último término, a un pánico bancario como el que ocurrió.

\subsection{Monetización del déficit fiscal}

A mediados de la década de 1860, debido a la Guerra con España, se produce un deterioro de las cuentas fiscales, con déficits de 5,2\% del PIB y 
FIGURA 10

DÉFICIT FISCAL Y DEUDA PÚBLICA EN RELACIÓN A LOS INGRESOS FISCALES

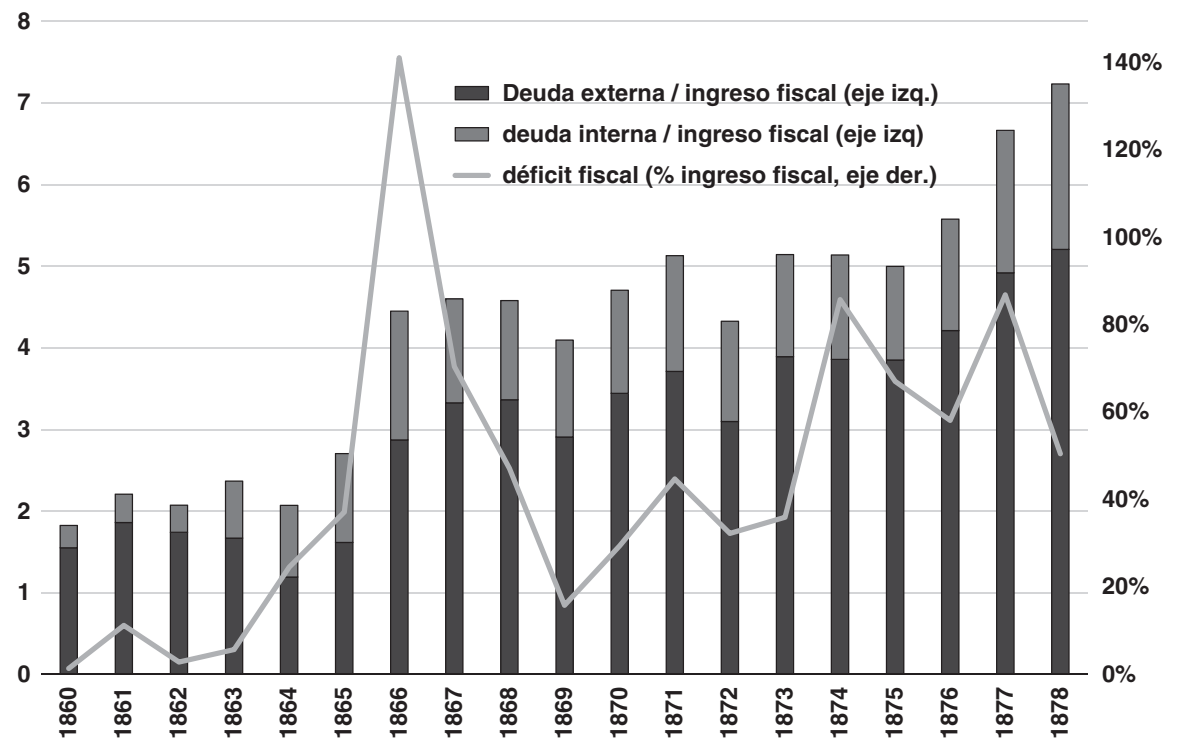

Fuente: Díaz et al. (2010).

3,9\% del PIB en 1866 y 1867, respectivamente. Si bien esta situación se modera en los años que siguen, entre 1874 y 1877 se vuelven a generar severos imbalances, con un déficit fiscal anual promedio de 3,5\% del PIB o $75 \%$ de los ingresos fiscales. Este empeoramiento estuvo estrechamente vinculado a las malas condiciones externas que mermaron la recuadación de derechos de aduana, ítem que representaba cerca del 60\% de los ingresos del fisco. Entre 1874 y 1877, la caída del comercio exterior significó una baja de $27 \%$ en los impuestos externos y de $16 \%$ en los ingresos totales del fisco. Aunque hubo diversas tratativas por aumentar la recaudación vía impuestos, estas fallaron (Sater 1979) y los déficits se financiaron recurriendo a la emisión de deuda, la que en 1877 representaba un $27 \%$ del PIB o 7 veces los ingresos fiscales (Figura 10). El Estado emitió deuda interna por $\$ 3$ millones en 1876 , por $\$ 5$ millones en 1877 y colocó bonos soberanos por un total de $£ 4,4$ millones en 1870,1873 y 1875 , momento a partir del cual el acceso al crédito externo se torna restrictivo (Sicotte et al. 2009).

Ante las dificultades para acceder al crédito externo, en octubre de 1877 el gobierno comienza a negociar un préstamo con los bancos (Conoboy 1976) 
emulando la figura utilizada en 1866: la concesión de privilegios de emisión. Estas negociaciones no solo fueron conocidas del público sino que, de acuerdo a la prensa de la época ${ }^{21}$, retomaban casi con exactitud los términos de una anterior tratativa liderada en 1876 por el entonces Ministro de Hacienda, Rafael Sotomayor. Las nuevas negociaciones fueron encabezadas por el Ministro de Hacienda, Augusto Matte, socio del Banco Matte y accionista del Banco Nacional. El 27 de marzo de 1878, el gobierno firmó un contrato de préstamo con nueve de los once bancos por un total de \$2.525.000. A cambio, los bancos recibieron el derecho de emitir billetes con el privilegio de ser aceptados a su valor nominal contra todo pago en favor del Estado hasta 1888. En principio esta emisión privilegiada era por cuatro veces los montos prestados pero los bancos podían incrementarla a prorrata hasta $\$ 12$ millones. La extensión de la emisión privilegiada a nuevos bancos implicaba que los bancos Nacional y Edwards, únicos tenedores de derechos del acuerdo de 1866, debían renunciar a ellos. Esta "renuncia" fue compensada por el Estado a través de una remuneración anual hasta 1888 y niveles de emisión privilegiada superiores al resto, tanto en términos absolutos como en relación a su capital. (Tabla 2).

Pese a haber participado de las negociaciones, los bancos de Valparaíso y de Concepción se marginaron del acuerdo. Una razón fue que el gobierno no estuvo dispuesto a aceptar su exigencia de poner fin al trato privilegiado del Nacional como agente exclusivo de las cuentas fiscales. Pero hay un segundo motivo más importante: lo limitado del monto de emisión privilegiada que se les ofrecía por los próximos veinte años. Esto es muy claro en el caso del Banco de Valparaíso cuyo préstamo al Estado hubiera sido de $\$ 700.000$ y su techo de emisión de $\$ 2.8$ millones o apenas $46 \%$ de su capital pagado. Esta proporción resultaba muy inferior a las de sus dos principales competidores y era menos de un tercio de la que le permitía la ley de 1860 y por la cual se hubiera regído si no participaba del acuerdo. Si bien no se conocen las razones precisas de por qué al Valparaíso se le ofreció un techo de emisión tan bajo, una alternativa plausible es que su gran competidor, el Nacional, haya operado en su contra aprovechando sus lazos con el gobierno. En un inserto publicado en el Diario el Ferrocarril (7/4/1878) dirigido a sus accionistas, el Banco de Valparaíso explicaba las razones de su negativa y calificaba el techo de emisión de "insignificante" respecto de su capital, implicando disminuir su circulación efectiva en: “\$663.000 menos que la circulación anotada en el último balance de febrero (1878) y un millón menos de nuestra circulación en abril del año pasado". Haber participado del préstamo también tenía una dificultad práctica. ¿De dónde obtendría los $\$ 700.000$ que debía transferir al fisco? A diferencia de otros bancos signatarios que sencillamente podían imprimir nuevos billetes (dado que

${ }^{21}$ El Ferrocarril, 14/02/1878. 
TABLA 2

EL PRÉSTAMO DE 1877-1878: MONTOS COMPROMETIDOS (\$ CORRIENTES)

\begin{tabular}{|c|c|c|c|c|c|c|}
\hline Banco & Préstamo \$ & $\begin{array}{l}\text { Emisión } \\
\text { privilegiada } \\
\text { (1) } \$\end{array}$ & $\begin{array}{l}\text { Techo de emisión } \\
\text { (\% del capital } \\
\text { efectivo) }\end{array}$ & $\begin{array}{c}\text { Extensión de la } \\
\text { emisión privilegiada } \\
\text { (2) } \$\end{array}$ & $\begin{array}{c}\% \text { del total de } \\
\text { emisión } \\
\text { "privilegiada" }\end{array}$ & Emisión -1 \$ \\
\hline Nacional & 1.100 .000 & 4.400 .000 & $110 \%$ & 5.227 .723 & $44 \%$ & 2.381 .472 \\
\hline Edwards y Cía. & 540.000 & 2.160 .000 & $144 \%$ & 2.566 .337 & $21 \%$ & 1.217 .930 \\
\hline Consolidado & 250.000 & 1.000 .000 & $67 \%$ & 1.188 .119 & $10 \%$ & 261.231 \\
\hline Matte y Cía. & 200.000 & 800.000 & $80 \%$ & 950.495 & $8 \%$ & 296.052 \\
\hline Alianza & 150.000 & 600.000 & $60 \%$ & 712.871 & $6 \%$ & 1.274 .609 \\
\hline Agrícola & 100.000 & 400.000 & $22 \%$ & 475.248 & $4 \%$ & 185.234 \\
\hline Unión & 75.000 & 300.000 & $75 \%$ & 356.436 & $3 \%$ & 54.212 \\
\hline Ossa y Cía. & 60.000 & 240.000 & $48 \%$ & 285.149 & $2 \%$ & 75.935 \\
\hline Mobiliario & 50.000 & 200.000 & $18 \%$ & 237.624 & $2 \%$ & 122.157 \\
\hline Total & 2.525 .000 & 10.100 .000 & & 12.000 .000 & $100 \%$ & 5.868 .832 \\
\hline
\end{tabular}

Fuente: Calculado a partir de los balances individuales y Ley del 27 de junio de 1878. Emisión-1, corresponde al monto de billetes en circulación inmediatamente antes del acuerdo de préstamo. 
tenían una circulación vigente inferior al nuevo techo de emisión), el Valparaíso no tenía márgen: a fines de 1877 ya contaba con más de $\$ 2.4$ millones en circulación. En el mismo inserto el banco señalaba que:

El desembolso de los $\$ 700.000$ [...] imponía al banco sacrificios muy efectivos, sacrificios que se nos ofrecía compensar con ventajas aparentes. La admisión de nuestros billetes en las oficinas y empresas del Estado solo habría tenido importancia para el banco: 1) si se hubiera señalado a nuestra emisión un límite proporcionado a nuestro capital; 2) si se hubiera establecido completa igualdad en las relaciones del gobierno con todos los bancos.

El Banco finalmente se preguntaba por las consecuencias de renunciar al privilegio. Confiaba en que su alto capital y el disponer de una amplia red de sucursales a lo largo de Chile le permitirían competir con los bancos privilegiados:

Estamos persuadidos de que la confianza pública será en todo caso la más sólida base de propsperidad del banco, i que consagrado nuestros esfuerzos a conservar $i$ robustecer esa confianza, no tendremos motivos de arrepentirnos por haber asumido una actitud que deja al Banco de Valaparaíso con su entera libertad de acción i al amparo de la lei común.

Si bien el préstamo fue aprobado formalmente por el Congreso el 27 de junio de 1878, se trató de un fait accompli. En efecto, luego del acuerdo formal de marzo de 1878, los bancos empiezan a traspasar las sumas comprometidas en cuatro pagos iguales el 1 de abril, el 15 de abril, el 1 de mayo y el 15 de mayo. El mismo proyecto de ley señalaba que si no se aprobaba antes del 1 de julio, los bancos podían exigir el reembolso inmediato de las sumas vertidas con una tasa de interés anual de $10 \%$.

Pese a que el préstamo de 1877/1878 replica la lógica del de 1866, existen dos diferencias importantes para dimensionar sus alcances. Primero, ambos préstamos ocurren en contextos monetarios completamente distintos. El préstamo de 1866 facilita la emergencia de un mercado bancario inexistente y se da en una situación de fuerte contracción monetaria en la que la emisión privilegiada no generó efectos inflacionarios ${ }^{22}$. En contraste, el acuerdo de 1877 se realiza en una industria madura y luego de una fase de expansión del crédito. El préstamo de 1877/78 permitía una emisión privilegiada por hasta $\$ 12.000 .000 .000$ o casi 5 veces los montos prestados. Esto implicaba duplicar la cantidad de billetes en circulación de los bancos signatarios (\$5,9 millones), incrementar en $70 \%$ el total de billetes del sistema y casi triplicar la cantidad de emisión privilegiada en la economía (desde

${ }^{22}$ Entre 1866 y 1868 la inflación fue de -0.1\% (Díaz et al. 2010). 
$\$ 4,5$ millones a $\$ 12$ millones). Segundo, al incluir a nueve de los once bancos existentes, el acuerdo anclaba a la casi totalidad del sistema bancario a una emisión privilegiada. Una de las razones dadas en el Parlamento para aprobar formalmente este préstamo fue precisamente que se hacía "justicia" ya que: "[...] el contrato permite poner fin al privilegio concedido a solo dos bancos y su extensión al resto de los bancos." ${ }^{23}$ Ligado con el punto anterior, el acuerdo también puede ser visto como un mecanismo de coordinación y fijación de participaciones de mercado entre actores que supuestamente compiten. Naturalmente, esto era contradictorio con los principios de banca libre y de competencia entre emisores.

\subsection{Incentivos a deteriorar la calidad}

En un sistema de banca libre con convertibilidad metálica, el billete de banco puede ser visto como una opción financiera que ofrece a su tenedor la posibilidad de convertirlo en metálico en cualquier momento. El equilibrio competitivo requiere que los billetes en una misma localidad se vendan a su valor par (Fama 1983, Gorton 1996, 1999) ya que si se vendieran con descuento existirían oportunidades de arbitraje. A su vez, el billete tiene un valor por el servicio financiero que presta como medio de intercambio (Klein 1974) y cuya aceptación es función, entre otros atributos, de las reservas metálicas del emisor para asegurar su conversión. En el equilibrio competitivo debe existir una calidad única que asegura la circulación de un billete como medio de intercambio, determinando que el "buen billete" domina al "mal billete". Cuando los agentes son capaces de diferenciar entre la calidad de las distintas "marcas" de billetes, el billete de un banco que deteriora su calidad o sobre emite es devuelto a su emisor mediante el mecanismo de "adverse clearings" (Dowd 1988, 1996; Selgin 1988, 1994, White 1984a).

El acuerdo de 1877/78 rompe este mecanismo disciplinador. Tomando como dada la participación de los bancos en el acuerdo (volveremos sobre este punto más adelante), las condiciones del mismo generan incentivos a que los bancos deterioren la calidad de sus billetes y sobre emitan. Para entender por qué, recordemos que todos los billetes de los bancos signatarios tendrían el privilegio exclusivo de ser recibidos por el fisco a su valor nominal. Es decir, gozarían del mismo valor legal, independientemente de su calidad medida por su respaldo metálico. Así, lo que indirectamente hace el fisco es fijar el tipo de cambio entre billetes. Al hacerlo emerge la famosa Ley de Gresham y el "mal billete" domina al "buen billete". Una vez dentro del acuerdo, la respuesta racional de cada uno de los bancos es a utilizar todo el techo de emisión privilegiada, sobre emitiendo y bajando la cobertura

23 Ramón Barros Luco, miembro de la Comisión de Finanzas y de la Industria y el ex Ministro de Hacienda (1872-76). En SCD, 12 de Junio de 1878. 
metálica. Ello sucede por dos razones. Primero porque el costo de aumentar la emisión es más bajo que si ésta tuviera que hacerse vía respaldo metálico. Segundo y más importante, porque el acuerdo configura un juego en el cual si el banco A sobre emite y el banco B no lo hace, la posición competitiva de B se deteriora. Ello ocurre ya que, a ojos del público, los billetes de los bancos A y B tienden a ser perfectos sustitutos dada su aceptación a valor nominal contra todo pago en favor del fisco. Es interesante constatar que durante la discusión del préstamo en el Parlamento, algunos diputados comprendieron perfectamente estos riesgos:

Debido a la emisión privilegiada, si por desgracia el préstamo es aprobado, nos llevará directamente a la inconvertibilidad y a una circulación superior a las que las condiciones actuales de la economía pueda absorber [...] A aquellos que concuerdan con este proyecto, les digo que no deben olvidar que nos llevará directo a un regímen de papel moneda [...] el fisco, consciente o inconscientemente estará garantizando a cada billete de banco de mala calidad y a cada banquero que experimente problemas ${ }^{24}$.

Bajo un régimen de convertibilidad metálica y una economía pequeña y abierta como la chilena, en principio existe un tipo de cambio fijo entre el peso y otras monedas como la libra esterlina ancladas sobre un padrón metálico (oro). Pese a la depreciación de la plata, Chile operaba de facto bajo un sistema bimetálico. Esto quiere decir que en un contexto de convertibilidad, si bien el tipo de cambio no era completamente fijo, sus variaciones eran pequeñas y estaban dentro de la banda de arbitraje definida por los puntos oro y plata (Briones 2004). El punto clave es que esto solo está garantizado en la medida que la conversión de los billetes sea creíble. El préstamo de 1877/78 atentaba contra esta credibilidad, generando expectativas de depreciación del peso. Hay dos formas de entender por qué. Primero, las condiciones del acuerdo debían generar una disminución del respaldo metálico de las futuras emisiones, empeorando así su capacidad de conversión. Segundo, un incremento sustancial de la emisión como la que derivaba del acuerdo, debía traducirse en un incremento del nivel de precios. En una economía abierta dónde tiende a operar la ley de un solo precio, este aumento de la inflación doméstica debe traducirse en presiones a la depreciación de la moneda local. La evidencia está en línea con el argumento anterior. La Figura 11 muestra que, a partir de octubre de 1877, se produce un marcado incremento de expectativas de depreciación del peso. Estas resultan de comparar el diferencial en las tasas de rendimiento entre los bonos del fisco denominados en pesos con los bonos soberanos chilenos, de igual duración, denominados

${ }^{24}$ Extracto del discurso del Diputado Ambrosio Montt. En SCD (10 de Junio de 1878: 58 y 63). 
FIGURA 11

SPREAD DEUDA PÚBLICA INTERNA (SANTIAGO, \$ CORRIENTES) Y DEUDA SOBERANA (LONDRES, $£$ ) (PUNTOS BASE, BPS)

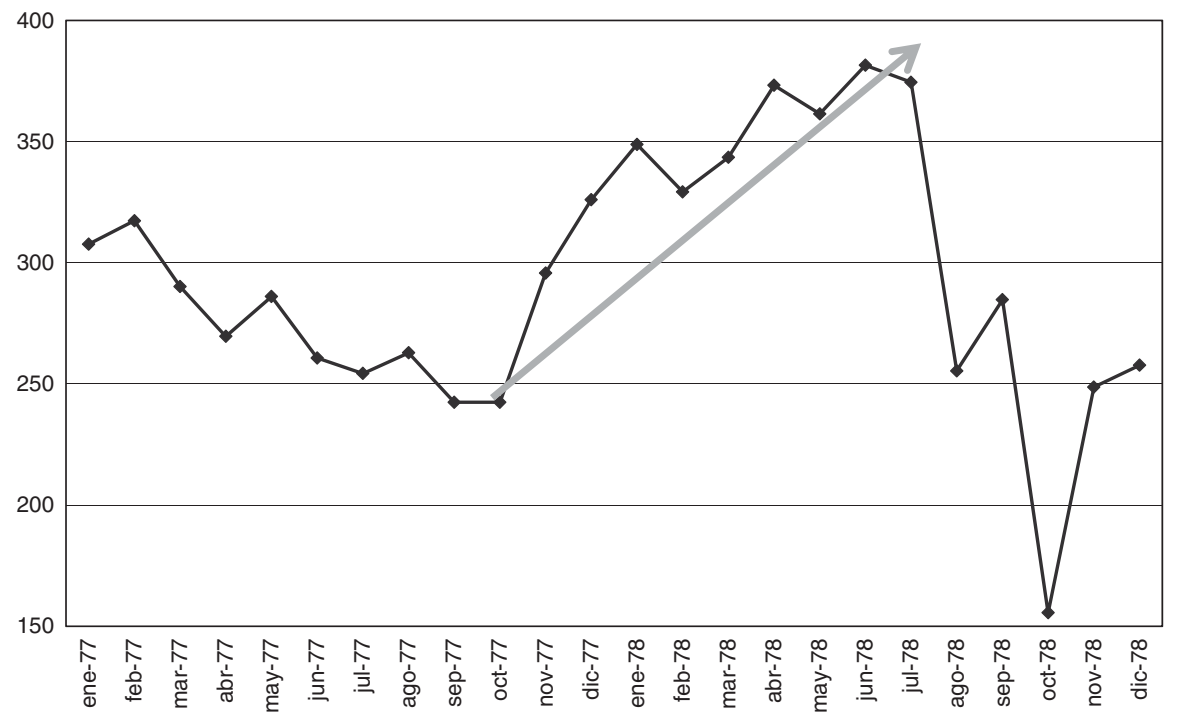

Fuente: Para la deuda soberana transada en Londres, Investor's Monthly Manual. Para la deuda pública transada en Santiago, Diario El Ferrocarril. Fechas en bibliografía.

en libras esterlinas ${ }^{25}$. Este resultado es concordante con Sicotte et al. (2009) quienes documentan que, a fines de 1877, se produce un aumento "inexplicado" del riesgo soberano chileno. La explicación podría deberse precisamente a expectativas de depreciación del peso inducidas por el acuerdo: dado que los ingresos del fisco son principalmente en moneda local, una depreciación hace menos probable el pago de las obligaciones fiscales en libras. Consistente con lo anterior, la figura muestra además que las expectativas de depreciación se revierten y estabilizan después que se decreta la inconvertibilidad de julio de 1878. Ello ocurre porque la depreciación esperada efectivamente se materializa: entre agosto y septiembre el peso perdió casi el $10 \%$ de su valor.

25 La intuición es la siguiente: para dos bonos de características similares, que tienen el mismo emisor (el Estado de Chile) y cuya única diferencia es que la deuda asociada es, en un caso, pagadera en pesos y, en otro caso en libras, una anticipación de depreciación de la moneda local debe compensarse con un aumento de la tasa de rendimiento del bono local (aumento del spread respecto a la obligación denominada en libras, como se muestra en el gráfico) o, lo que es lo mismo, con una baja de su precio relativo. 


\subsection{El pánico pancario: un resultado esperable}

Habiendo mostrado que el resultado esperable del acuerdo era a la sobre emisión y a la depreciación del peso, lo que sigue es entender por qué esto podía generar un colapso bancario. La razón es simple. Un tenedor de billetes prefiere tener un peso fuerte en la mano que uno depreciado. Cuando los agentes anticipan que el peso se depreciará, lo racional es ir al banco a convertir sus billetes por metálico y recomprar esos billetes una vez que el peso se deprecie. Con bancos con reservas fraccionarias, resulta clave ser el primero en llegar al banco: si llega a tiempo obtiene el valor en metálico del billete, pero si llega tarde no obtiene nada. La corrida bancaria se produce.

Si el acuerdo podía tener como resultado esperado un colapso del sistema, ¿por qué el fisco decide proponerlo? Como vimos, una parte importante de la respuesta es que necesitaba imperiosamente cubrir sus importantes déficits fiscales y su acceso al crédito externo era limitado. Por otra parte, en caso de colapso del sistema, el fisco siempre podría rescatar a los bancos decretando la inconvertibilidad o bien imprimiendo sus propios billetes, diluyendo así el costo de su actuar (es lo que hizo). ¿Y qué pasa a nivel de los bancos? ¿Por qué deciden suscribir el préstamo si podía llevar a un pánico? La respuesta deriva de una situación análoga al dilema del prisionero. Si bien para el sistema bancario en su conjunto participar del acuerdo, sobre emitir y generar una crisis no resultaba deseable, para los bancos individualmente considerados era una estrategia racional: tener una emisión privilegiada facilitaba la circulación de sus billetes y no tenerla los hacía estar en una posición desventajosa respecto a los que la tienen (el precedente de los privilegios de 1866 era claro). Bajo estas condiciones, el incentivo individual era a participar del acuerdo y a sobre emitir ${ }^{26}$. Esto es particularmente cierto en el caso de bancos pequeños enfrentados a un banco grande como el Nacional cuya condición de cuasi banco estatal e historial de privilegios hacía altamente factible que participara del préstamo al fisco. El incentivo de los bancos a participar se ve exacerbado, además, al considerar que un 45\% de los parlamentarios era accionista de los bancos Ross (2003:116-17), siendo razonable suponer que, en caso de dificultades, estos apoyarían un salvataje. A su vez, los bancos Nacional, Edwards, Valparaíso y Mobiliario tenían, cada uno, dos directores miembros del parlamento y el Banco Agrícola tres ${ }^{27}$.

26 Es importante notar que en la decisión de participar, los intereses de los directores de los bancos parecen haber estado razonablemente alineados con los de los accionistas. Por definición éste era el caso en los bancos constituidos comos sociedades de responsabilidad ilimitada. En cuanto a los bancos que eran sociedades anónimas, como ya vimos, sus directores eran, en conjunto, accionistas relevantes.

27 A los datos reportados por Ross (2003), se ha agregado el Banco Agrícola y se ha complementado la información para el Banco Mobiliario. 
TABLA 3

INCITACIONES A SOBRE EMITIR

\begin{tabular}{|c|c|c|c|}
\hline & & \multicolumn{2}{|r|}{ NAC } \\
\hline EDW & NS & $\begin{array}{c}\text { NS } \\
0 ; 0\end{array}$ & $\begin{array}{c}S \\
-K ;+1\end{array}$ \\
\hline & $\mathbf{S}$ & $+1 ;-K$ & $-K(1-P)+P G ;-K(1-P)+P G$ \\
\hline
\end{tabular}

Analicemos más formalmente el argumento anterior. Primero tomaremos como dada la participación de los bancos en el acuerdo y mostraremos que, pese al colapso esperado, la sobre emisión es la opción racional para los bancos individualmente considerados. Enseguida extenderemos el resultado para mostrar que también resultaba racional participar del acuerdo. La Tabla 3, permite modelar primer caso. Por simplicidad asumimos que existen dos bancos idénticos (EDW y NAC) neutrales al riesgo. Cuando ningún banco sobre emite (NS) la ganancia diferencial de cada banco es 0. Si un banco sobre emite (S) pero el otro no (NS), suceden dos cosas. Por un lado el banco que sobre emite obtiene una ganancia adicional que normalizamos a la unidad. Esta ganancia proviene del señoriaje asociado a la mayor emisión, la menor tenencia de reservas y a su expansión en el mercado de depósitos. Por otro lado, el banco que no sobre emite deteriora su posición competitiva. Suponemos que este deterioro es tal que la circulación de ese banco se reduce a cero y el banco quiebra perdiendo su capital $(\mathrm{K})^{28}$. $\mathrm{Si}$ ambos bancos sobre emiten, se produce una corrida bancaria y los dos bancos pierden su capital (K). Sin embargo existe una probabilidad (P) de que el Estado rescate a los bancos decretando la inconvertibilidad de los billetes. En ese escenario los bancos subsisten y obtienen una ganancia subsecuente de G. Basta con que G y P sean positivos (como lo son), para que la sobre emisión sea la estrategia dominante: independientemente de la decisión que un banco tome (S o NS), para el otro banco siempre resulta más conveniente adoptar la estrategia $\mathrm{S}$ que la NS.

Es importante notar que, tanto su tamaño (too big to fail) como la relación estrecha que mantenía con el gobierno, hacen razonable pensar que el Nacional apostara a un salvataje del Estado en caso de problemas. En el modelo anterior, esto deriva en que los incentivos del Nacional a participar del acuerdo se ven exacerbados. A su vez, dado el tamaño de ese banco ( $50 \%$ del mercado), el incentivo a la participación de los restantes bancos, condicional a la participación del Nacional, también se incrementa.

${ }^{28}$ Este supuesto es consistente con la ventaja absoluta que tiene el billete privilegiado sobre el que no lo es. El argumento es particularmente válido, además, en el caso de un banco pequeño que se enfrenta a uno grande como el Nacional. 
La extensión del resultado anterior a la decisión de participar o no en el acuerdo es trivial. Dado que la estrategia dominante, condicional a la participación en el acuerdo, es a sobre emitir, entonces la decisión de no participar en el acuerdo es análoga a participar en él y decidir no sobre emitir. Como vimos esta opción no es de equilibrio.

\subsection{Epílogo}

En julio de 1878, cuando las reservas metálicas del Nacional casi se habían agotado, sus autoridades le piden al gobierno la inconvertibilidad. Según el diario El Mercurio de Valparaíso (25/07/1878), el 20 de julio el director del Nacional, Melchor Concha y Toro, tiene una audiencia con el Ministro de Hacienda, Augusto Matte, a tal efecto. Al día siguiente, se produce una reunión entre José Besa, director gerente del Banco Nacional, Agustín Edwards Ross y Jorge Ross, director y director gerente del Banco Edwards, respectivamente, y varios ministros ${ }^{29}$. El Banco Edwards se oponía a darle una salida al Nacional. Sin embargo, el poder de negociación de este último era elevado. No solo por la relación privilegiada que mantenía con el Estado, sino que también porque el Estado tenía deudas con el banco (líneas de crédito). Tal como señalaba el banquero Agustín Ross: "Esta deuda del Gobierno con el Banco sirvió como argumento para que puediera influir en el Congreso y acordarle la ley de inconvertibilidad"30. Finalmente Edwards aceptó las condiciones reclamadas por el Nacional y firmó el borrador del proyecto de inconvertibilidad. La noche del 21 de julio, éste fue presentado al Congreso que había sido convocado con urgencia y operó en sesión secreta. El proyecto fue aprobado por unanimidad en el Senado y por 45 votos contra 9 en la Cámara de Diputados ${ }^{31}$. Originalmente, la ley de inconvertibilidad solo consideró a los nueve bancos signatarios del préstamo, confiriéndoles la inconvertibilidad y el curso forzoso, no por los billetes que efectivamente tenían en circulación en ese momento, sino por todo el techo de emisión privilegiada establecido en el préstamo de 1877/78. En septiembre de 1878 una modificación de la ley incorporó a los bancos de Valparaíso y de Concepción, previo préstamo al fisco de $\$ 1.000 .000$ y $\$ 125.000$, respectivamente. De esta forma, el Banco de Valparaíso obtuvo un $40 \%$ más de emisión que la del acuerdo de 1877 que rechazó, mientras que el total de emisión inconvertible y de curso forzoso quedó definitivamente fijado en $\$ 15.010 .000^{32}$.

${ }^{29}$ Al momento de la reunión, Concha y Toro era vice-presidente de la Cámara de Diputados (también había sido Ministro de Hacienda 1869-70), mientas que José Besa era Senador suplente. Agustin Edwards Ross, del Banco Edwards, era diputado.

30 Ross (1910:36). Ross fue director del Banco Edwards en los 1880s.

31 SCD (sesión secreta), 22/07/1878.

32 Ley del 6 de septiembre de 1878. La emisión inconvertible de los bancos Valparaíso y Concepción quedó fijada en cuatro veces los montos prestados. Adicionalmente, la ley amplió en 
La inconvertibilidad era supuestamente una medida transitoria, estando previsto el retorno a la convertibilidad metálica para 1879. En la práctica, el papel moneda seguiría siendo la norma hasta 1895. La razón es que, a partir de 1880, el Estado empieza a efectuar emisiones inconvertibles y de curso forsozo, reemplazando al metálico como activo de conversión para las emisiones de los bancos privados. De esta forma, 1878 marca el fin de la banca libre en Chile en un sentido estricto de emisión privada y convertibilidad metálica.

\section{CONCLUSIÓN}

Pese al liberalismo teórico de la Ley de Bancos de 1860, entre 1860 y 1878 el sistema bancario chileno se fue alejando progresivamente del ideal de banca libre que Courcelle-Seneuil, su mentor, tuvo en mente. Tempranamente el Estado desarrolló una relación estrecha con los bancos que aceptaron prestarle dinero para financiar sus déficits fiscales a cambio de la concesión de privilegios de emisión. A su vez, el gobierno tuvo un vínculo particularmente estrecho con el principal banco del país, el Banco Nacional, el que se fue transformando en un cuasi banco estatal. Esta relación entre banca y gobierno tendría consecuencias a la hora de explicar el descalabro de 1878.

Uno de los elementos esenciales de la banca libre consiste en que los bancos compitan por que sus billetes sean aceptados por el público. La lucha por señalar la calidad de sus emisiones es fundamental para inhibir la sobre emisión y asegurar que el "buen billete" domine al "mal billete" como medio de pago. Una condición necesaria para esto es que exista flexibilidad en la tasa de cambio entre billetes de tal forma que el "buen billete" sea preferido al "mal billete". Este mecanismo disciplinador esencial se pierde si es que hay una desconexión entre la calidad del billete y esta tasa de cambio. Eso es exactamente lo que ocurrió con un préstamo por sumas considerables negociado por el Estado y los bancos a fines de 1877. La particularidad de dicho préstamo es que garantizaba que la emisión de los bancos préstamisas fuera recibida a valor nominal contra todo pago en favor del Estado. Por esa vía, independientemente de la calidad de los emisores, sus billetes tenían el mismo valor legal. En este trabajo he planteado que ello generó incentivos a la sobre emisión y expectativas a la depreciación de la moneda local, siendo de esta forma esperable una corrida bancaria como la que se produjo desde fines de 1877 y que termina en la inconvertibilidad y el curzo forsozo en julio de 1878.

Irónicamente, un poderoso argumento en la dictación de la Ley de 1860 era la confianza en que bajo un sistema de bancos de emisión privado se

(footnote continued)

$\$ 410.000$ el techo conjunto de emisión inconvertible de los bancos Agrícola, Mobiliario y Ossa respecto a la emisión privilegiada que habían recibido previamente con el contrato de préstamo. 
eliminaba la tentación de que un emisor estatal pudiera monetizar sus déficits fiscales. Esa era la convicción de Courcelle-Seneuil ${ }^{33}$. Pero este supuesto estuvo lejos de materializarse en el caso chileno. Las relaciones entre el Estado y los bancos fueron diezmando esa ventaja de un sistema de emisión privado. El el punto cúlmine de esa historia fue el préstamo de 1877/ 78 , préstamo que se erige en una explicación fundamental a la hora de entender la crisis bancaria de 1878 .

El caso chileno es una valiosa experiencia dentro de la literatura de episodios de banca libre. Subraya la importancia de la economía política y, en particular, del vínculo entre banca y gobierno. Un vínculo que debe ser mirado con atención a la hora de analizar los casos históricos y calificarlos como ejemplos de banca libre.

\section{BIBLIOGRAFÍA}

Aranguiz, H. (1993): «Notas para el Estudio de los Bancos Extranjeros en Chile: 1889-1971». Historia 27, pp. 19-68.

Briones, I. (2004): Free-Banking: The Idea and the Reality. The Chilean Experience 1860-1898. Ph.D. Dissertation, Sciences-Po, Paris.

Briones, I. y Rockoff, H. (2005): «Do Economists Reach a Conclusion on Free-Banking Episodes». Econ Journal Watch 2 (2), pp. 279-324.

CaLomiris, Ch. y Khan, CH. (1996): «The Efficiency of Self-Regulated Payments Systems: Learning From the Suffolk System». Journal of Money Credit and Banking 28 (4), pp. 767-797.

Calomiris, CH y Haber, S. (2014): Fragile by Design: The Political Origins of Banking Crises and Scarce Credit. Princeton, N.J.: Princeton University Press.

CARR, J. y Mathewson, F (1988): «Unlimited Liability as a Barrier to Entry». Journal of Political Economy 96 (3), pp. 766-784.

CheckLand, S. G. (1975): Scottish Banking: A History, 1695-1973. Glasgow: Collins.

Conoboy, P. J. (1976): Money and Politics in Chile, 1878-1925, Ph.D. Dissertation. University of Southampton, U.K.

Courcelle-Seneuil, J. G. (1857): Bancos de Circulación. Santiago, Chile: Revista de Ciencias y Letras, pp. 37-50.

Diaz, J.; LüDers, R. y WAGNER, G. (2010): La República en Cifras. EH Clio Lab-Iniciativa Científica Milenio. URL: http://www.economia.puc.cl/cliolab.

Dow, Sh. (1996): «Why the Banking System Should Be Regulated». Economic Journal, Royal Economic Society 106 (436), pp. 698-707.

DowD, K. (1988): «Automatic Stabilizing Mehanisms under Free-Banking». Cato Journal 7 (2), pp. 643-659.

Dowd, K. (1994): «Competitive Banking, Banker's Clubs, and Bank Regulation». Journal of Money, Credit and Banking 26 (2), pp. 289-308.

DowD, K. (1996): «The case for Financial Laissez-Faire». The Economic Journal 106 (436), pp. 679-687.

ECheverri, L. M. (1991): Free Banking in Colombia, 1865-1886. Ph.D. Dissetrtation, University of Georgia.

${ }^{33}$ Courcelle-Seneuil (1857:45). 
Economopulus, A. (1988): «Illinois Free Banking Experience». Journal of Money, Credit and Banking 20 (2), pp. 249-264.

EsPinoza, R. (1909): Cuestiones Financieras de Chile. Santiago, Chile: Imprenta Cervantes.

FAMA, E. (1983): «Financial Intermediation and Price Level Control». Journal of Monetary Economics 12 (1), pp. 7-32.

Fetter, F. (1931): Monetary Inflation in Chile. Princeton University Press.

Fuentealba, L. (1945): Courcelle-Seneuil en Chile. Errores del Liberalismo Económico. Santiago, Chile: Prensas de la Universidad de Chile.

Goodhart, Ch. (1988): The Evolution of Central Banks: A Natural Development? Cambridge, MA: MIT Press.

Goodspeed, T. B. (2016): Legislating Instability: Adam Smith, Free Banking, and the Financial Crisis of 1772. Harvard University Press.

Gorton, G. (1996): «Reputation Formation in Early Bank Notes Market». Journal of Political Economy 104 (21), pp. 346-398.

Gorton, G. (1999): «Pricing Free Bank Notes». Journal of Monetary Economics 44, pp. 33-64.

Grossman, R. y ImaI, M. (2013): «Contingent capital and bank risk-taking among British banks before the First World War1». The Economic History Review 66 (1), pp. 132-155.

HabER, S. (2008): «Political Institutions and Financial Development: Evidence from the Economic Histories of Mexico and the United States», en Haber, S., North, D. C. y B. Weingast, (eds.), Political Institutions and Financial Development. Stanford University Press.

Hammond, B. (1957): Banks and Politics in America: From the Revolution to the Civil War. Princeton University Press.

HAYeK, F. A. (1976): Denationalisation of Money. The Argument Refined. London: Institute of Economic Affairs.

Hickson, CH. y Turner, J. (2002): «Free Banking Gone Awry: The Australian Banking Crisis of 1893». Financial History Review 9 (2), pp. 147-167.

Hickson, CH. y Turner, J. (2004): «Free Banking and the Stability of Early Joint-Stock Banking». Cambridge Journal of Economics 9 (6), pp. 903-919.

Hirschman, A. O. (1963): «Inflation in Chile», en Hisrshman, A. O. (ed.), Journeys Toward Progress. New York: The Twentieth Century Fund, pp. 159-223.

Iftekhar, H. y Dwyer, G. Jr (1994): «Bank Runs in the Free Banking Period». Journal of Money, Credit and Banking 26 (2), pp. 271-88.

Jeftanovic, P. y Luders, R. (2007): «La Banca Libre en Chile». Documento presentado en el Primer Congreso Latinoamericano de Historia Económica (Cladhe I), Montevideo, Uruguay.

KING, R. (1983): «On the Economics of Private Money». Journal of Monetary Economics 12 (1), pp. 127-158.

KLeIN, B. (1974): «The Competitive Supply of Money». Journal of Money, Credit, and Banking 6 (4), pp. 423-53.

LlonA, A. (2000): «Chile During the Gold Standard: A Successful Paper Money Experience», en Martín Aceña, P. y J. Reis (eds.), Monetary Standards in the Periphery: Paper, Silver and Gold, 1854-1933. New York: St. Martin's Press, pp. 174-206.

Mayo, J. (1987): British Merchants and Chilean Development, 1851-1886. London: Westview Press.

Meisel, A. (1992): «Free banking in Colombia», en Dowd, K. (ed.), The Experience of Free Banking. London and New York: Rutledge, pp. 93-102.

Millar, R. (1994): Políticas y Teorías Monetarias en Chile 1810-1925. Santiago, Chile: Universidad Gabriela Mistral. 
Morón, E. (1993): La Experiencia de Banca Libre en el Perú, 1860-1879. Lima: Centro de Investigación de la Universidad del Pacífico.

Nazer, R. (2000): «La fortuna de Agustín Edwards Ossandon: 1815-1878». Historia 33, pp. 369-415.

Ossa, N. (1888): Ligeros Apuntes Sobre el Establecimiento y Desarrollo de los Bancos de Emisión en Chile. Valparaíso, Chile: Revista Económica, n9, pp. 97-112.

RocкоғF, H. (1974): «The Free Banking Era: A Reexamination». Journal of Money, Credit and Banking 6 (2), pp. 141-167.

Roскоғғ, H. (1985): "New Evidence on Free Banking in the Unisted States». American Economic Review 75 (4), pp 886-89.

Rolnick, A. y Weber, W. (1983): «New Evidence on the Free Banking Era». American Economic Review 73 (5), pp. 1080-1091.

Ross, C. (2003): Poder, mercado y Estado. Los bancos en Chile en el siglo XIX. Santiago, Chile: Lom Ediciones.

Ross, A. (1886): Los Bancos de Chile y la Lei que los Rige. Valparaíso, Chile: Imprenta Excelsior.

Ross, A. (1893): El Problema Financiero. La acción de los Bancos de Emisión para Producir la Situación Actual en Chile. Valparaíso, Chile: Imprenta del Universo de Guillermo Helfman.

Ross, A. (1910): Le Chili 1851-1910. Soixante ans de questions financières, d'études monétaires et de problèmes des banques. Valparaíso, Chile: Editorial no identificada.

Santelices, R. (1893): Los Bancos Chilenos. Santiago, Chile: Imprenta y Encuadernación Barcelona.

SATER, W. F. (1979): "Chile and the world depression of the 1870's». Journal of Latin American Studies 11 (1), pp. 67-99.

Schuler, K. (1992): "The World History of Free Banking: an Overview», en Dowd, K. (ed.), The Experience of Free Banking. London and New York: Rutledge, pp. 7-47.

Selgin, G. (1988): The Theory of Free Banking: Money Supply under Competitive Note Issue. Cato Institute, Rowman \& Littlefield Publishers.

Selgin, G. (1994): «Free Banking and Monetary Control». The Economic Journal 104 (427), pp. 1449-1459.

Selgin, G. y White, L. (1994): «How Would Invisible Hand Handle Money?». Journal of Economic Litterature 32 (4), pp. 1718-1749.

SicotTe, R.; VizcaRRA, C. y WandSCHNEIDER, K (2009): «Military conquest and sovereign debt: Chile, Peru and the London bond market, 1876-1890». Cliometrica 4 (3), pp. 293-319.

Sylla, R. (2006): "Political Economy of Financial Development: Canada and the United States in the Mirror of the Other, 1790-1840». Enterprise \& Society 7 (4), pp. 653-665.

TAub, B. (1985): «Private Fiat Money with Many Suppliers». Journal of Monetary Economics 16 (2), pp. 195-208.

Subercaseaux, G. (1922): Monetary and Banking Policy of Chile. Oxford: Clarendon Press, Humphrey Milford.

White, L. (1984a): «Competitive Payments Systems and the Unit of Account». American Economic Review 74 (4), pp. 699-712.

White, L. (1984b): Free Banking in Britain: Theory, Experience, and Debate, 1800-1845. Cambridge University Press.

ZegarRA, L. F. (2013a): «Free banking and bank entry in Latin America». Investigaciones de Historia Económica 9 (3), pp. 131-142. 
Zegarra, L. F. (2013b): «Free-Banking and Financial Stability in Peru». Journal of Austrian Economics 16 (2), pp. 187-226.

ZEGARRA, L. F. (2014): «Bank laws, economic growth and early banking in Latin America: 1840-1920». Explorations in Economic History 53, pp. 101-119.

\section{Fuentes}

- Sesiones de la Cámara de Diputados, República de Chile (1859; 1878).

- Sesiones Oridinarias del Senado, República de Chile (1865).

- Memoria del Ministerio de Hacienda, (1876)

- Investor's Monthly Manual, Londres, $(1877,1878)$

Diarios:

- El Ferrocarril (Santiago): fechas en texto

- Diario El Telégrafo (Chillán): fechas en texto.

- The Chilean Times (Valparaíso): fechas en texto

- El Mercurio de Valparaíso: fechas en texto

Fuentes de datos para Figura 11:

1. Diario El Ferrocarril (Chile), (3/01/1878) ; (14/1/1877) ;(11/3/1877) ; (8/4/ $1877)$; $(6 / 5 / 1877) ;(3 / 6 / 1877) ;(8 / 7 / 1877) ;(2 / 9 / 1877) ;(6 / 10 / 1877) ;(4 / 11 /$ $1877)$; $(2 / 12 / 1877) ;(5 / 1 / 1878) ;(3 / 2 / 1878) ;(10 / 3 / 1878) ;(7 / 4 / 1878) ;(15 / 5 /$ $1878)$; $(9 / 6 / 1878)$; $(22 / 6 / 1878)$; (13/7/1878) ; (10/8/1878) ; (14/9/1878) ; $(12 / 10 / 1878) ;(10 / 11 / 1878) ;(8 / 12 / 1878)$.

2. The Investors Monthly Manual (London), (27/6/1877) ; (24/2/1877); (31/3/ $1877)$; $(28 / 4 / 1877)$; $(26 / 5 / 1877)$; $(30 / 6 / 1877)$; $(28 / 7 / 1877)$; $(25 / 8 / 1877)$; $(29 /$ 9/1877) ; (27/10/1877) ; (24/11/1877) ; (29/12/1877) ; (26/1/1878) ; (23/2/1878) ; $(30 / 3 / 1878) ;(27 / 4 / 1878) ;(25 / 5 / 1878) ;(29 / 6 / 1878) ;(27 / 7 / 1878)$; $(31 / 8 / 1878)$; $(28 / 9 / 1878)$; $(26 / 10 / 1878)$; $(30 / 11 / 1878)$; $(28 / 12 / 1878)$. 